rot 2,150

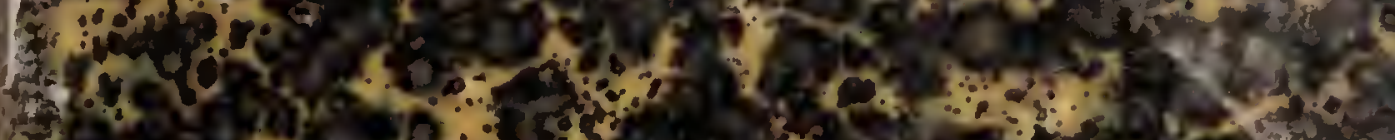

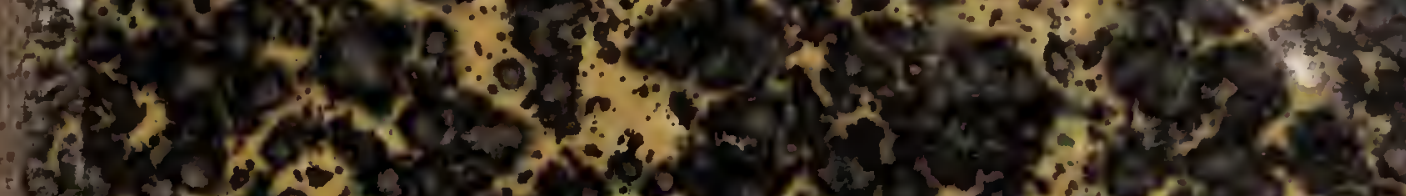
020 ? 13

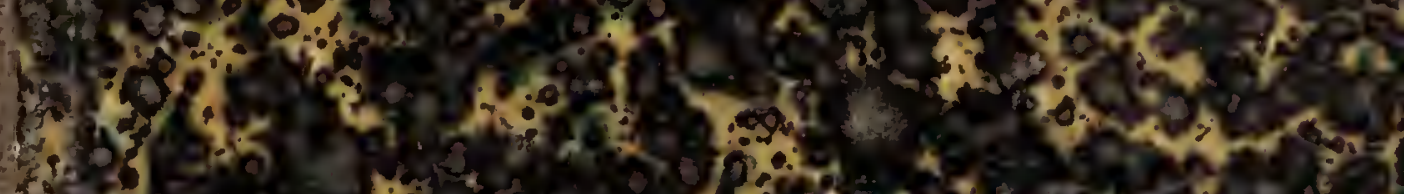
$7.5 \times 5 \%$

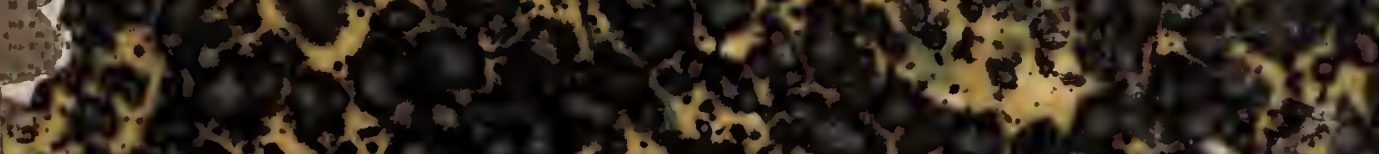

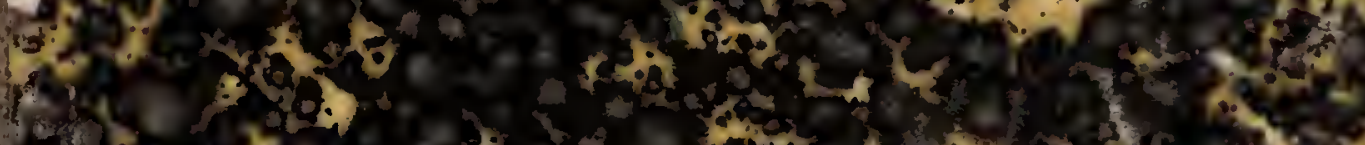

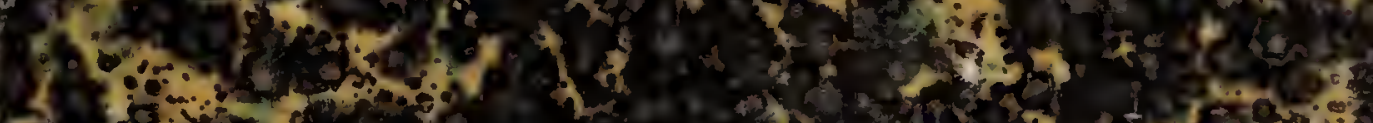

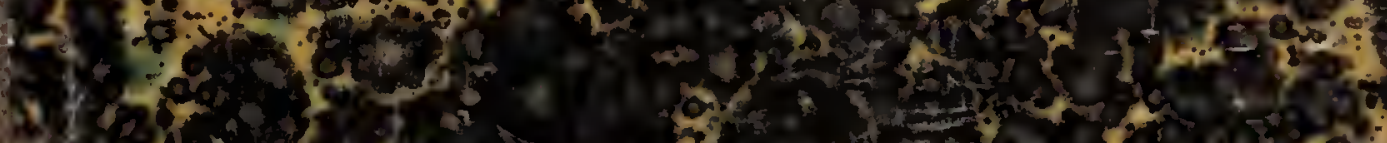

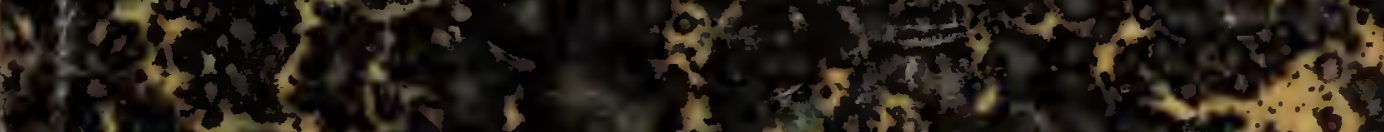

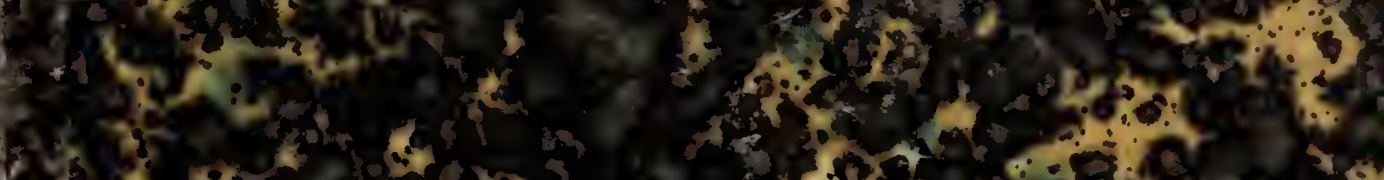

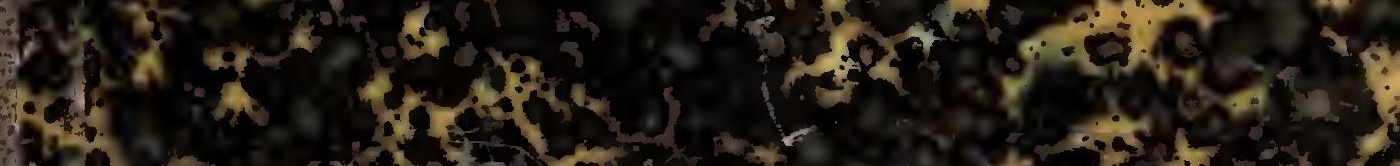

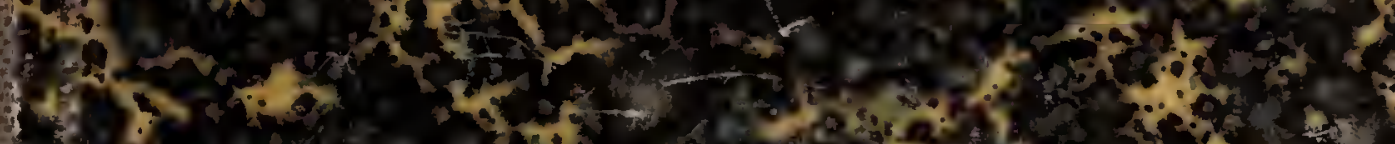

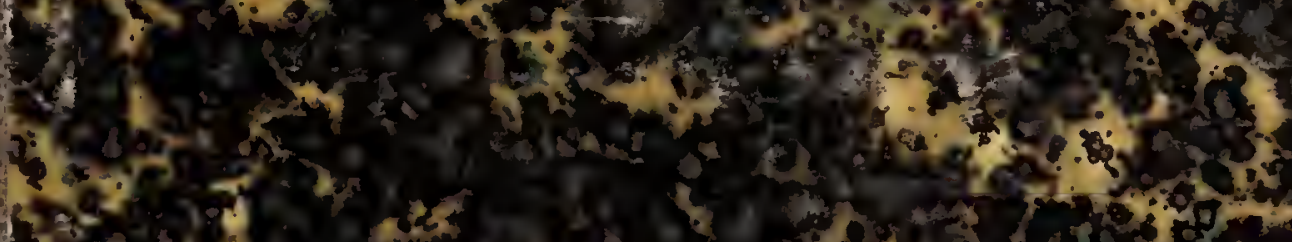

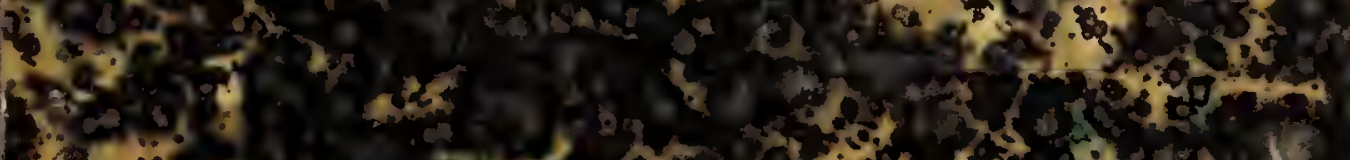

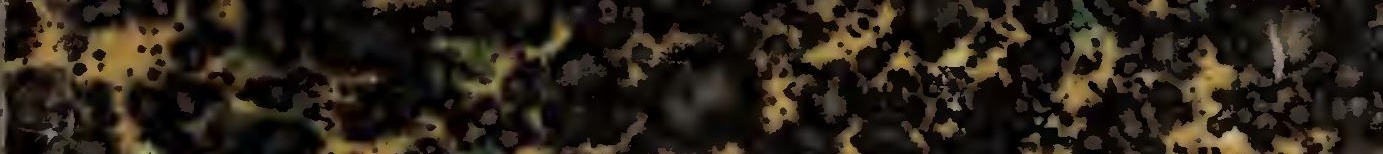

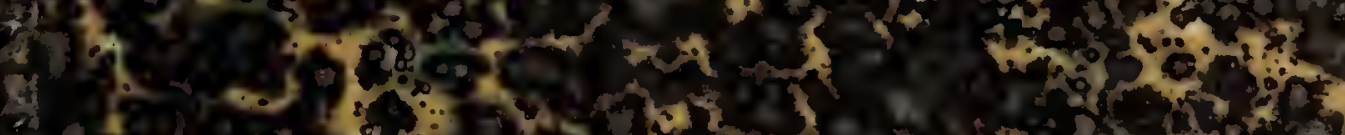
1. 77930 5 - 12015 the

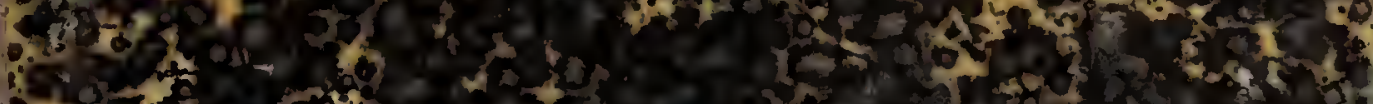

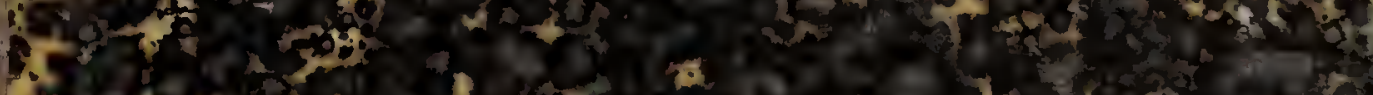

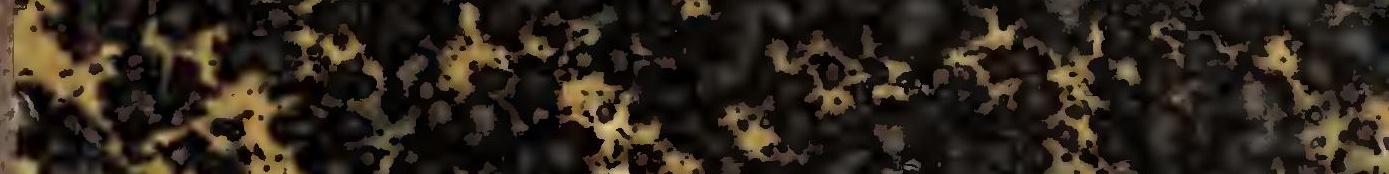
$y=1$. 2.

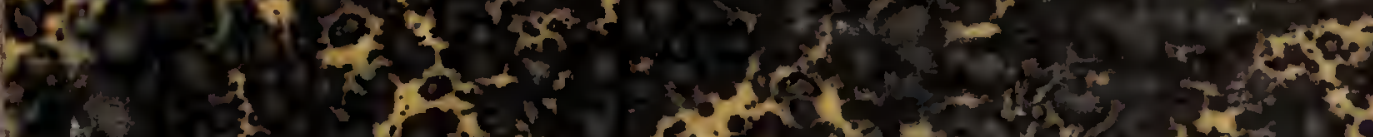
41 (5)

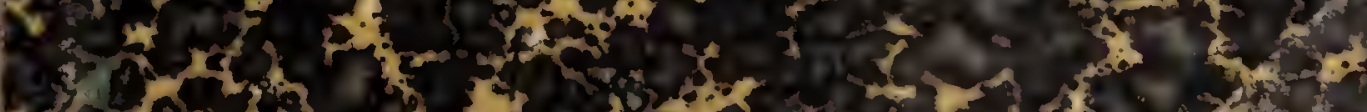

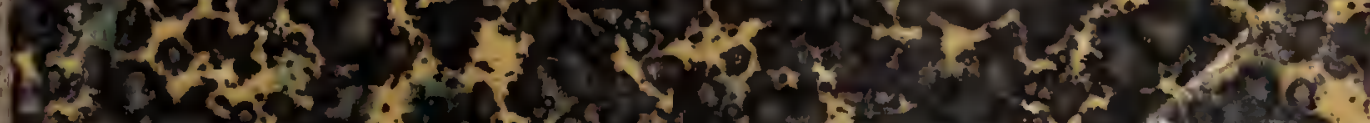

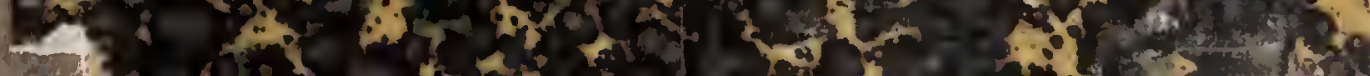




\section{Or 8}

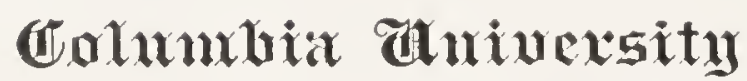
in the city of grew gloxk

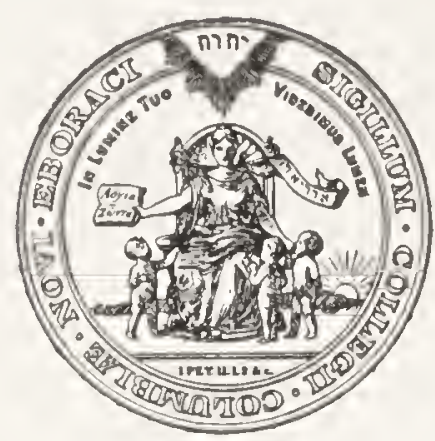

gitixaxy 






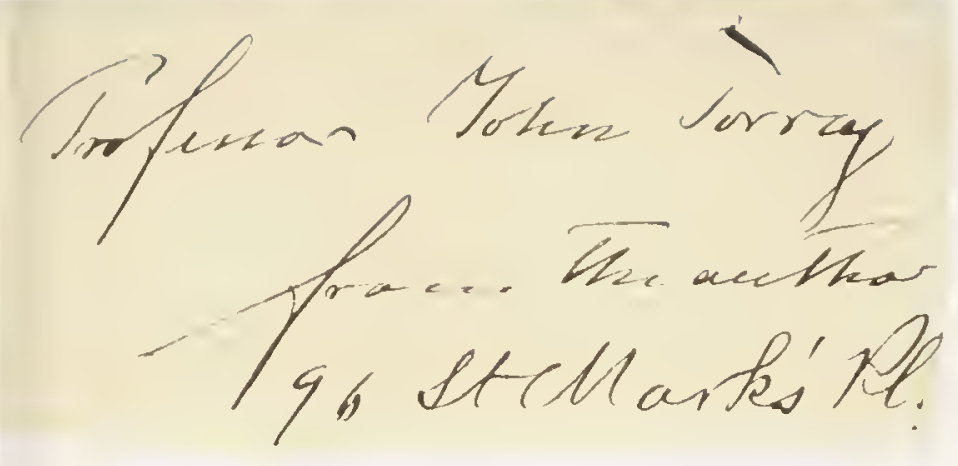

(Af Naturhist. Foren. Vidensk. Meddelelser 1858.)

\section{Palmae Centroamericanae.}

$$
\text { Ancture A. S. Örsted. }
$$

'́libus I. A pecinae.

\section{Chamacorona Willd.}

Demne Slege hler grundet af Willdenow (Act. Berol. 1804 p. 41) paa den af Jacquin i Hort. Schocnbr. (2. 65. 1. 247, 248) under Narn af Borassus pinnalifrons beskrevne Palme og udmaerker sig navnlig red Trebohlomster, flere hindeagtige Hylsterblade, som kranmerhusformigt omslntte deu lange Kolbestilk, Mangel af Dakblade, et lille tredect ydre og et större, oftest trebladet. indre Blomslerdicklic. Martius fiiede hertil Nunnezharia fragrans Ruiz et Pav., Martinezia limearis Ruiz ef Pav., M. Ianceolata Ruiz et Pav., alle fra Pern, en Art fra Brasilien (C. palmillora) or senere 5) af schiede og Deppe i Mexico opdagede Arter (C. elatior, Schiedrana, clegans, oblongata, concolor). Ved Licbmanns Reise i Mexico (1S40-43) bler delle Lands Flora beriget med ikke farre end 21 rye Palmer (Orersigt orer det kongl. danslie Vidensk.'s Selskahs Forhandlinger $1815 \mathrm{Nr}$. 1). Af disse henförte Martius (Hist. Palm. 3. 30\%) 11 Arter til denne Slagt, idet han - men som jeg skal säge at rise nden Grund - inddrog to af Lielmann opstillede nye Slaggter, Stachyophorbe og Collinia, som Underslagter under Chamaedorea. I de Aar; som cre forlöbne, sillen det store Vierk af Martius over Palmeme afsluttedes (18.j0), have Chamadorecrne, som liemhöre til de skjomneste blande alle 
Palmer, og som paa Grund af deres ringe Störrelse isar egne sig lit Dyrkning i Drivlusene, i fortrinlig Grad værel Gjenstand for de Botanikeres og Plantesamleres Opmærksomhed, der have bereist det tropiske Amerika, og Arternes Antal er derved blevet bragl op til henved 50. Da de fleste af disse tilhöre den centralamerikanske Flora, da ombyggelige Analyser af et stort Antal Arter have viist mig, at flere vigtige Forhold i Blomstens Bygning ere blerne oversete af tidligere lagltagere, og da jeg fremdeles ved nermere Kjendskab lil de af Liebmann opstillede Arter seer mig istand til at parise flere Urigtigheder $i$ de $i$ den senere Tid beskrevne Undersliegter og Arter, skal jeg her forsöge at levere nogle Bidrag lit en kritisk Revision af den hele Slægt.

Allerede red at see hen til den store habituelle Forskjel, som er saa iöinefaldende ved en Betragtning af alle de af Martims lil Chamaedorea henförte Arter, af hrilke nogle have enkelte, andre sammensalle Blade, nogle en udeelt, andre en grenet Kolbe, af hrilke hos nogle det gdre og det indre Blomsterdicklie ere eensdannede, medens hos andre dette sidste er forholdsmessig stort og kronagtigl, maalte man formode, at en Sondring i flere Sliggter vilde vare orereenstemmende med de nII almindelig gjeldende systematiske Regler. Denne her ogsaa foreslaaet af Liclumann, idet han henförte de Arter, som have et sambladet, linı i Spidsen tretandet, indre Blomsterdxkke og klappet Knopleie los legge Kjön, til Slagten Collinia og de, som have en ndeell IIankolbe og alle 3 Rum udviklede i lrugten, lil Stachyophorbe. Disse to Sliegter maac ansees for rel begrundede, og del kan neppe billiges, naar de af Martius og andre Forfattere henföres som Undersiegter under Clamacdorea. Vel har Dr. Klotzsch sügr at hevde Stachyophorbes Ret som Slægt (Otto 11. Dietrich Allg. Gartenz. 1852. 363), idet han herlil lenförer cul Art, som af Warsecwicz var hagh fra Ginatemala (S. Deckeriana); men demne Plante er — som led ril sees af nedenstaicnde Beskrirelse - i culver Henseende 
saa forskjellig fra de af Liebmann lil Stachyophorbe henförte Arter, at der iklic kan vare Tale om at forene dem i samme Sligt. Stachyophorbe Deckeriana Kl. maa saaledes danne Typus for en egen Slagt, som jeg foreslaaer at kalde Dasystachys. Denne er ligesom den af Dr. Klotzsch opstillede Underslagt Stephanostachys meget rasentlig afvigende fra alle andre Chamaedoreer ved Hanblomstens Bygning. Hos disse er nemlig Hanblomstens indre Blomsterdække forneden stærlit indsnævret og sammenvoxet med Stövtraadene og den rudimentare Stövvei, saa at herved opstaaer en solid Stilk - et Forhold som markeligt nok hidtil er bleven aldeles overscet; hos Dasystachys derimod og Stephanostachys, som ogsaa i andre Henseender slutle sig nöre sammen, mangler Hanblomstens indre Blomsterdakke denne Stilk, og dette er ilke sammenvoxet med Stövdragerne, der ere frie i deres liele Langde ligesom ogsaa den rudimentare Stövei. Stephanostachys vil saaledes ikke kunne henföres som Underslagt ti] Chamaedorea; men da de herlil regnede Arter desuden ere meget afvigende red Hunblomstens Bygning, den korte Kolbestilk, de store Hylsterblade og meget tatsiddende Blomster, saa maa den ansees for en vel sondret Slagt. Det samme gjolder om den af Wendland opstillede Underslagt Eleutheropetalum (Index Palmarum p. 58); thi de herunder indbefattede Arter ere ikke alene, saaledes som det angires af denne Forfatter, forskjellige fra Colliıia, med lwilke de stemme overeens i det klappede Knopleie, ved et tribladet indre Blomsterdakke i Hunblomsten, men de frembyde ogsaa andre vasentlige Egenheder i denne, idet Frugtknuden bestaaer af tre fuldkomment sondrede triangulare Partier, som kun ere forenede red en falles Midtsöile, og det indre Blomsterdaklies Blade ere foroven tykke, kjödede, lavalvede og röde, forneden meget tynde, hindeagtige og livide.

Efter disse Forandringer vil Slagten Chamaedorea komme til at indbefatte de Arter, hvis Hanblomster have et stilket indre Blomsterdakke med klappet Knopleie og ofte i Spidsen sammenvoxne Flige, livis Hunblomster have et fribladet indre 
bomsterdake med overtullel-laglingt Knopleie, og som nasten uden Ludlagelse have fimede Blade og grenede Kolber. Endng efter denne meget snarrere Begrendsuing frembyde de til Chamaedorea henhörende Arter saa store Forskjelligheder, narnlig i IIunblomstens Form, at det vil vere nödvendigt at sondre dem $\mathrm{i}$ 4 Underslegter, som jeg i det Fölgende skal söge at charahterisere.

Chamacdorecrne ndgjöre sailedes en egen lille Crupure (Subtribus) i Arecincernes Tribus, som narnlig udmarkin sim ied Treboblomster, Nangel af Dabblade og red den for alle amerikanste Arecineer eiendommelige skjeve Udvikling af Fruglen. Af Frugtknudens tre Rum udvikles som hos de fleste Palmer hun det ene under Frugldannelsen, men da delle ike roxer lige meget til alle Sider, men især paa Rygsiden, sa skerr der herred en Sankning af Bugsider, hrorved Arrenr, som oprindelig vare endestillede, tilsidst komme til at sidde ved Grunden af Bugsiden. De herhenlürende 7 Strgter kunne adshilles pail den i nedenstaaende Orersigt anginne Maade.

Chamacdorecac.

Flores dioeci. Bracteolite nullace. Stigmatia demum hasilaria, rentralia.

1. Perigonio interiore floris mascul. basi cum filamentis " germine rudimentario in stipite solido connato. Antheris crectis.

a) Praclloratione ulriusque sexns ialvala.

a) Perigonio interiore utriusque sexus gamophlyllo trilentato.............. Collinia Lhm.

B) Perigonio interiore lloris

fem. triphyllo.... Eleullieropetalum Wendl.

1) Praefloratione flor. mase, valuali, llor. fem. imbricala.

(e) hacea tricoceal ...... Stachyophorlin L.hm.

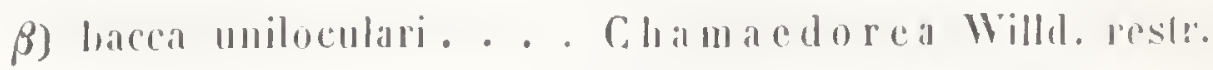

2. Prerigonio interiore floris mascul. stipitu sappius carente. Aurlocris oblique incumbentibus.

a) Stipite mullo.

a) Spadice utrusque sevus simplici (lloper feminno com-

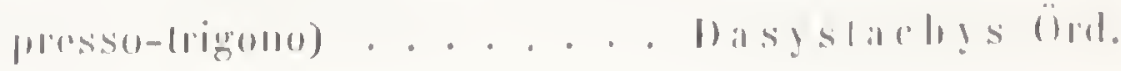


B) Spadice ntrimsquo sexus lamoso.

(llore fomineo depresso-globoso). . Stephanostachys Kl.

b) Stipite brevi.

Floris masce perigonio exteriore tubuloso, interiore obovato, laci-

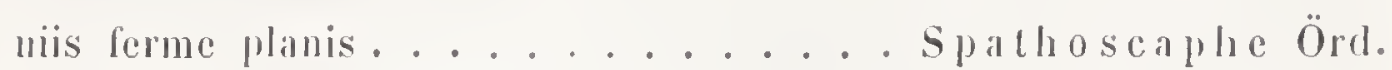

\section{Collinia Jbm.}

Perigonium exterius cupulare, calycinum, trifidum; perigonium interius multo majus, crassiusculum, corollinum, llavescens, trilentatum 8 . trifidum, in flore mase. stipitatum globosum, in flore fem. ovatum. Bacca parra globosa. - Caudex gracilis, ercelus. Folia pinnata, pinnis numcrosis anguste lanceolatis strictis. Spadices sacpius duplicatoramosi (masc. majores, laxi) in pedunculis longissimis gracilibus inter folia persistentia enatis spathis cylindricis membranaceis arcle raginantilus omnino tectis; rami graciles, flores remoti, distichi.

Demne Sliegt er ikke alene i Jilomsteus Bygning; men ogsal i sin hele Habitus saa afrigende fra Chamadorea, at det vilde rere meget urigligt at antage den af Martius foreslaade Forening. Bladene ere altid forsynede med mange Smaablade; disse cre meget smalle. langl tilspidsede, stive, ved Grunden lidt sammenböiede, slijert fasthrftede til den felles Bladstilk, og Randen i Nirheden af Spidsen paa den ene Side indadböict. Den faclles Blomsterstilk er meget lang og tynd, teet omsluttet af hinleaglige Iylsterblade og komence frem mellem Bladene. Kollocu er mere grenet end hos de andre Clamaedoreer (isaer Hanlolben). og Grencne meget tynde. Blomsterne sidde fjernt fra himanden og ere toradede, saa at deres Stilling her er $\frac{1}{3}$ medens den i kegelen er $\frac{a}{3}$. Barrene ere meget sma og runde. Sex Arter re lijente, al hrillic fem fra Mexico.

C. (?) fiblosa Wendl. Index palm. 57 . Da Blomsterne ikkr endmu ere kjendte, er det tvivlsumt, hropidt deme Art lö̈rel herhen. Den alskiller sig i Blatenc fia de andre Arter narnlig dervod, al Sulabladenc sidde 4-7 sammen i Hobe. Den antiges at have hjemme i Guatemala. 
C. elegans (Harto) Limnaca 5. 204. - Otto u. Dietr. Gartenz. 1831. 145. 245. Den er fundet af Schicde i Mexico, og ligeledes af Liebmann, som angiver, at den er almindelig i Östsiders Urskove fra 15 til $22^{\circ}$ n. Br. mellem 1500 og 3000 Fod. (Overs. orer Vid. Skr. 1815 p. S).

C. elatior Lbm. I. c. - Chamaedorea Liebmanni Mart. Hist. Palm. 3. 308. Den har bredere Smaablade end de andre Arter, og Hunblomstcns indre Blomsterdiklie er tredeelt. I Chinantlas Bjergskove imellem 2-3000'.

C. lutmilis Llum. I. c. - Mirt. Hist. Palm. 3. 308. Kolbens Greme udeelte. Smabbladene ere liengere og smallere end hos C. elegans. De Exemplarer, Liebmann har truffet i Mexico, maae alle have vierel unge, da han angiver, at de nasten mangle Stamme; i vor bolaniske Have findes nemlig Planter med ell $3 \frac{1}{2}$ Fod höi Stamme, men Stxngelleddene ere horte (1" lange). I Mexicos östlige Urskore imellem 1500$3000^{\prime}$.

Ifölge Klotzsch skal den Palme, som ofte dyrkes under Navn af Kunthia Deppei, lıenhöre til denne sliegt, og ligeledes skal Heller have bragt en ny Art fra Mexico. Klotzsch foreslater at kalde den förste C. Deppeana, den sidste C. Helleriana (Otto 1. Dietr. Gartenz. 1S52. 362).

\section{Elentheropetalum Wendl.}

Flores masc. Perigonium exterius patelliforme, membramaceum, albescens, leviter trifidum; perigonium iuterius globosum tripartitum, crassiusculum, aurantiacum, basi in stipitem compressum contractum, practoratione valvatum. Flores fem. Perig. exter. fere 3phyllum in scrobiculis immersum, foliolis membranaceis albescentibus rotundatis concaviusculis; perig, inter. triphyllum, foliolis oblongis superue crassis carnosis concavis aurantiacis inferne tenuissime membranaceis subdiaphanis allescentibus, pracloratione valualis. Staminodia 6 triangularia v. lau- 
ceolata. Ovarium oblongun v. depresso-glubosum, in parle superiore valvmlis axi cohacrentibus ceterum liberis. Stigmata 3 reflexa. Bacea ovalis v. oblique ovata, albumine corneo, embryone dorsali. - Caudes clatus, erectus, remolius annulatus. Folia pinnata v. subsimplicia, vaginis breviluus latissimis rigidis sulcatis oblique apertis, pinuis paucis latioribus. Spadices inter folia persistentia cnati, pedunculo communi longiusculo spathis membranaccis omnino teclo; masculi ramosissimi, inferne duplicaloramosi, ramis tenuibus longissimis glaucescentibus diffusis patentibus pendulisve, feminei simplices v. parce ramosi, ranis crassis erectis angulatis albidis. Flores aurantiaci, remoli, feminei ii) scrobiculis immersi.

Eleutheropetalum betragles af Wendland som en Underslagt al Chamaclorea; men navnlig Junblomsterne frembyde saa mange ciendommelige Forhold, al der ikke kan vare nogen Trivl om, at det er rigligst at sondre den som en egen Slagt, der red del hlappede Knopleie sluller sig narmest lil Collinia, men ellers er meget forskjellig fra denne. De vigligste Slagtscharakterer bestaac i IIunblomstens hindeaglige, luvidlige, nasten fribladede ydre Blomsterdakk og det indre Blomsterdakkes store farvede, foroven meget tykle, forneden hindeaglige, aldeles frie Blade. Iferlil kommer endnu fruglimuden, som foroven bestaaer af tre fric lrekantede, kun ved Midlaxen forenede, Partier. De korle, meget brede, klövede Bladskeder, de nasten enkelte eller kun al fa brede Smabblade sammensalle Blade og de röde Blomster, som hos Humplanten ere nedsankede $i$ en udeelt eller kun af faa oprette, kantede, hvidlige Grene dannet Kolbe, give desuden de herhenhörende Arter el ciendommeligt og let gjenkjendeligt lrag. Bierenc ere större curl hos de andre Slagter.

E. Ernesti Augusti Wendl. Ind. Palm. 5̧S. - Chamactorea Wendl. in Otto u. Dietr. Gartenz. 1852. 73. - Morenia Wendl. in Otlo u. Dielr. Gartenz. 1853. 3.

Folia simplicia, lamina ovalo-oblonga bifida v. irregulariter pinnalifissa, superne margine exleriore grosse serrata. Spadices 
feminci simplices, stricti, folia aequantes r. superantes; rachis crassa carnosa. Floris fem. foliola perig. exter. subacqualia, rotundata, concaviuscula, albidi, inferne fuscescentia. Staminodia lriangularia parva. Ovarium oblongum, staminodiis 4-jies longius. (vidi specimina ex lort. Herrenlusano).

Denne Art er af Wendland benarnt efter Koug Erust August af Hannover i Anerkjendelse af denne Fyrstes store Interesse for Palmekulturen og henhöler lil de skjönneste blandt alle Chamaedoreer. Den dyrkedes tilligere under Navn af Chamacdorea simplicifrons, Geonoma latifrons og Hyospathe elegans og ulmarker sig ver enkelte udeelte eller uregelmassig declte $\mathrm{i}$ Rauden saugtakkede Blade, en udeelt kjödel Hunkolbe, som under Befrugtningen opsvulmer til en Tykikelse af $\bar{\tau}$ Linier, og store masten 9" lange skjavt xgformede Bar. Den skal liave lijemme i Tabasco.

Til denne Slaegl henlörer foruden ovennarnte Ałt Chamacdorea Sartorii Lbm. (Mart. 1. c. 308), der uden Tivl er den samme, som af Wendland er beskevet under Narn af Morenia oblongata $\beta$ conferta. (Olto 1 . Dietr. 1. c. 1853. 3). Den er meget forskjellig fra den foregaaende red fintede Blade og ved Hnnkolben, som bestaaer af 6-S oprette Grenc. Desudeu er i ITunblomsten de to af det ydreblomsterdakkes Blade meget bredere end det tredic, og de ere alle mere haxhedéeud hos E. Ern. Aug. og lidt lilspidsede pa Midten. Fruglkmuden er nedtrykt kugleformig. De lancetdannede Staminodier nate mesten op lil Toppen af Fruglinuden. Exemplarer bragte at Liebmanu fra Mexico, hyor den roser i Bjerghlöfler paa $19^{\circ}$ 1 . Br. unellem 2000 og 2500 fods IIjide, have blomstret i vor botaniskir Have. Den stater meget naer Cham. oblongala Mart. (I. c.3. 160 , Wendland in Otto u. Dietr. Garlenz. 1553. 3), om den ilhe cr en Varietel af samme.

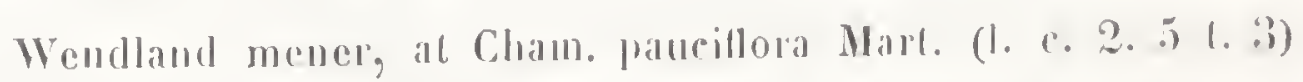

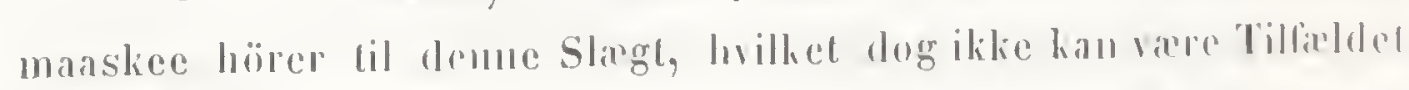
ifölge Martins's Beskrivelse af Hunhlomstens indre Blomsterdakide. 


\section{Stachyophorloe Lichno.}

Flores masc. Perigonium exterius cupulare: membranaceum, trilobnu, interins multo majus, obovatum, tripartitum, basi cum filamentis et pistillo rudimentario in stipitem solidum contractum, lacinis oblongis subcarnosis, prafloratione valratis. Flores fem. Perigonium exterius fere maris, interius oratum substipitatum, foliolis late ovatis acutiusculis subcarnosis margine membranaccis. Ovarium lrigonum depressum, stigmatibus minutis reflexis. Bacca bi-tricocca (fructus loculis sacpius omnibus cvolutis baccac tres stigmatibus centralibus basilaribus persitentibus conjunctac). - Caudex gracilis, abbreviatus, dense annulatus, procumbens (an semper?). Folia pinnata erecta $v$, erecto-patentia, pinnis alternis lincari-lanceolatis. Spadices masc. pedunculati ramosi, ramis gracilibus declinatis; fem. simplices longe r. longissime pedunculati, crecti.

Denne Slagt har hidtil kun varet meget ufuldstiendig kjendt, og den af Licbmann meddecle torte Beskrivelse er i flere vasentlige Punkter ilie overenstemmende uned Naturen. Hanblomstens indre Blomstcrdakke er nemlig sambladet ligesom los de andre Chamacdoreer og dels Knopleie klappet; Hunblomsteu derimod har overrullet-taglagt Knopleic. Martius betragter stachyophorbe som Inderslagt af Chamaedorea, hrorimod Klotzsch har sögt at havde dens Ret som Sliegt: men han laar ikke kjendt logen af de Arter, hvorpaa Liebmann har grondet sin Slagt, og den Art, som han troer at kunne henföre liertil, er i enhver Henseende saa afvigende, at deu. som jeg slial söge at vise i det Fölgende, maa danne en egen Slagt. Stachyophorbe er imidlertid en velbegrundet Slagt. Dens vasentligste Charahterer bestaner i det agformede indre Blomsterdakke, der ogsa hos Hunblomsten er noget stilket, i den trekintede naesten treklappede nedtrylite Frugtknude $o g$ navnlig i Frugtens Beskaflenhed, idet alle Frugtknudens tre Rum udvikles og det paa en ganske eiendommelig Maade. Frugtknuden sienker sig nemlig i Midten ontrent som hos Boragincerne og Labiaterne, saa at Arrene blice grundstillede, og de tre Rum omdannes til tre sondrede Bar, 
som kun ere forenede ved de midtstillede Ar. Betegnelsen "bacca tricocea" er derfor rigtigere end "bacca triloba", som anvendes af Martius - nemlig hos Sabal og Chamacrops, hror et lignende Forhold finder Sted -, da vi her have tre sondrede Smaafrugter. Herhen liöre kun 3 Arter, som have hjemme i Mexico og Jen nordlige Deel af Centralamerika.

S. cataractarum Lichm. - Mart. I. c.

Caudex 1-2' Ig. Folia longe petiolata erecta; pinnis utrinsecus 9-11 lineari-lanceolatis. Spadices fem. foliis multo breviores.

- Omhring Cataracterne i Chinantlas Bjergklöfter paa 12-1500. Höide (Liel)mann).

S. moutana Liebm. Mart. I. c. - Chamaedorea (Stachyophorbe) oreophila. Mart. I. c.

Caudex 3-4' Ig. Folia brevius petiolata erecto-patentia, piunis utrinsecus? elongato-lanceolatis. Spadices fem. Jongissime pedunculati folia superantes. - I Bjergskovene i Depart. Oajaca paa 3000-3,500' Höide (Liebmann).

S. pygmaca (Wendl.). - Chamaedorea pygmaea Wendl. in Ollo แ. Dietr. I. c. 1852. 21\%. Caudex abbreviatus procumbeus. Folia brevipetiolata, $16-17^{\prime \prime} \lg$., vaginis apertis, pimnis utrinsecus 9-12 elongato-lanceolatis. Spadices fem. foliis breviores, $10-12 "$ Ig. (vidi spec. ex lıort. Herrent.)

Denne Art er den nindste af alle Palmer (1 $\left.\frac{1}{2}\right)$ og udenerker sig ved en rigelig Udvikling af Blomster. Den er indfürt af Linden i de belgiske Haver og har ifölge Etiquetten paa det af mig fra Haven i Herrenhausen undersögte Exemplar hjemme i Chiapas.

Chamacelorea Willd. restr.

Flores masc, perigonium exterius patelliforme tribloum, interius multo majus globosum r. oblongum, tripartitum, basi cum filamentis el pistillo rudimentinio in stipitem solidum compressum contractum, Jaciniis apice liberis vo coadnatis, praclloratione valvalis. Flores fem. e basi subrotunda globosi r. ohlongi vel c 
Jasi lata ovali depresso-conici el in scrobiculis inmersi. Perig. exter. cupulare v. patelliforme, trilobum, virescens, interius triphyllum, foliolis virescentibus v. flavesecutibus praefloratione convoluto-imbricatis. Staminum sacpius rudimentum nullun. Ovarium ovalum v. subglobosum v. e basi lata depresso-conicum. Bacca globosa v. ovata ovalisve, albumine corneo, embryone dorsali $v$ basilari. - Caudex abbreviatus v. elatus, electus $v$. procumbens. Folia pinnata, rarissime simplicia. Spadices inter vel infra folia enati, longe pedunculati, spathas membranaceas pedunculum vaginantes perrumpentes, ramosi, ramis masc. saepius longissimis pendulis. Flores imprimis fem. minutissimi, virescentes $v$. flavescentes.

Efter den Begrandsning, som her er givet Slægten Chamaedorea svarer den i det Vasentlige til Underslagten Euclamacdorea hos Martius og Wendland. Den vigtigste Charakteer bestaace i overrullel-taglagt Knopleie hos Hunblomsten og större Overecnsstemmelse i Form og Farve mellem det ydre og indre Blomsterdakke end den, der findes hos de andre Slagter. Wendland deler de herlıenhörende Arter i to Grupper, eftersom det indre Blomsterdakkes flige hos Ilanblomsten ere frie eller sammenvoxne i Spidsen; men Hunblomsterne frembyde meget vasenlligere forshjelligheder, som saa meget bedre kunne lagges til Grund for en Inddeling, da de staae i Forbindelse med habituelle Egenheder. Samtlige til Chamacdorea henhörende Arter liunue lierefter fordeles i 4 vel adskilte Underslagter.

\section{Subgenus 1. Euchamacdorea Subg. n.}

Flores feminei minutissimi, e basi oblongo-ovali lata depressoconici, in scrobiculis immersi. Perig. exter. patelluforme trilobun, lobis conniventibus perig. interius obtegentibus. Perig. interioris foliola sacpius subreniformia, ovarium arcte amplectentia. Ovarium e basi lata conico-globosum, stigmatibus exsertis. Baccae (an semper?) ovatae. - Caudex gracilis, erectus, 3-12' altus. Folia mediocria (2--4'), erecto-patentia, raginis cylindricis longis apice 
oblipue apertis subatriculatis, pimuis paucis $(3-S)$ elongalooblongis membranaceis subsigmoideis. Spadices infra comam ereclopitentes, jedunculo lougo.

Den Art, som oprindelig ligger til Grund for Slaglen Clatmacdorea, Borassus pinuatifrons Jace., danner Typus for den förste Underslagl. Hunblomsterne ere meget sma og lave cu cicudommelig Form, idet de fra en aflang Grund danue en flad liegle og ere nedsienkede i Gruber. Hertil kommer en egen Habitus los alle herlienhörende Arter; de ere nemlig sma Palmer uncd en tyud opret Stamme med lange Led, med korte Blade, sou kun bestaac af faa, brede, lynde s-formig krummede Smaablade, og med grenede, langstilkede Kolber, som sidde nedenfor Bladenc. Hunkolbens Grene blive efter Befrugtningen lykke og lijödede og danne red deres röde Farve en smuk Modsatming lil de sorte Bacr.

$$
\text { C. (Eucliamacdorca) Pacaya sil. n. }
$$

Candex gracilis erectus subflexuosus remole anmulalus, $8-10^{\prime}$ altus. Folia pinnata erecto-patentia, $2-3^{\prime}$ longa, ragiuis cylindricis striatis quinquepollicaribus apice oblique apertis auriculatis, auriculis scariosis in petiolum adsccndentibus, peliolis raginam acquantibus r. hacce brevioribus rachique triquetris supra canaliculatis: pinnac utrinsecus $\gamma$, alternac, binac subapproximalac, obscure virides, membranaceac, plicatac, Ievissime sigmoideocurvalac, mediac oblongo-lanceolatae, 7 - 8 "longac, 1:" latac, longe acuminatac, infimis angustioribus, summis duobus multo latioribus superuc inargine exteriore serratis. Spadices fem. fructiferi 19 " lomgi; pedunculus compressus, inferme caulici appressus, 14" lougus, spathis (in specimin. meis jam ferme delapsis), ul ridelur, 5 - 6 fuscescentibus techss; rachis brevissima $1-1$ longa, subllexuosa, rami 5-6, 3-4pollicares, adrecti. Baccae oblique obovatac, basi ventrali stigmatibus coroualac, $1-5$-." longac. Embryo in medio dorso.

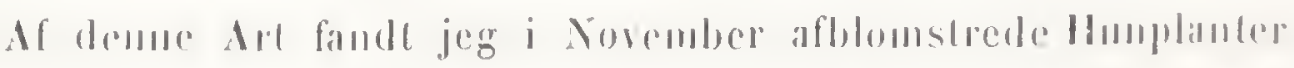
i forgtige Sliove pat Bjerget Jaris i Costa Rica i culloide af 
c. 3,000'. De aflange dybe Ciruber i Kolbegrenene rise, at don mat hïre til denne Undrosliegl: den stemmer ogsaa i Habitus orereens med de andre Arter, men er let kjendelig red sine smat hindeaglige foldede Smaablade, som i Form og Störrelse komme narmest til dem hos C. lepidola, fra livillie de log adskilte sig red en större Brede og starkere Krumning.

C. (Euchamacdorea?) bifurcata sp. n.

Pusilla, gracillima. Caudex ut videtur procumbens, in specim. jam frucliferis vix pedem longus, 4"“ crassus; internodia $1 \frac{1}{2} "$ longa. Folia pinnata $1 \frac{1}{2}-2$ ' longa, erecto-patentia; vaginac cylindricae membranaceac apice oblique apertae, $2 \frac{1}{2}$ longac; petioli triquelre, supra canaliculati, $2 \frac{1}{2}-3 "$ longi el rachis dorso fascia albida notali; pinnac utrinsecus 4 , alternae, binac approximalac, lanceolatac, subsigmoideo-curvatac, membranaceac, subplicatac, longe acuminatac, 6" lougac, $12-14$ " latac, duobus superioribus (e duobus in quovis latere confluentibus compositis), duplo latioribus oppositis, nervus medius valde obliquus, secundarii utrinque $3-4$ prominuli. Spadices fem. infra comam erecto-pateutes, S" longi. Pedunculus gracillimus, compressus, inferne appressus, 6 " longus, spathis (in specim. meis jam ferme delapsis) 5, ut videtur, tecti. Rachis evanescens in ramos duos lipollicares erectos, fructiferos divergentes divisa. flores densissimi, semiglobosi, virescentes. Perigoniun striatum, foliolis interiorihus rotundatis concavis. Baccar globosac, nigrae, Pisi magniludinc. Embryo subbasilaris.

Jeg liar fundet deme smuklic lille Palme paa Bjerget Aguacate i Costa Rica (1,509') i Bjergklïfter med Blomst og Frugt i November. Den er meget afrigende fra alle Arter af denne Understiegt red sin ringe Störrelse, ved sma Blade, somi kun lave I Smaablade par luver Side, og red Midtuervens Retuing. Midtnerven gataer hos alle Chamadoreer foroven noget ud mod den ene Side, men hos deme ligger den i den iverste Deel af Bladel me-

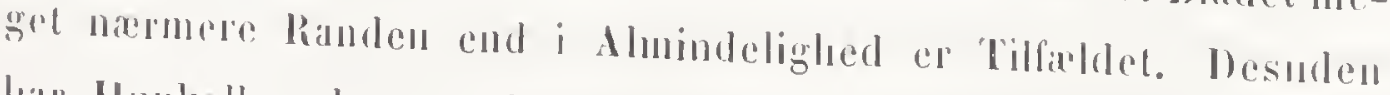

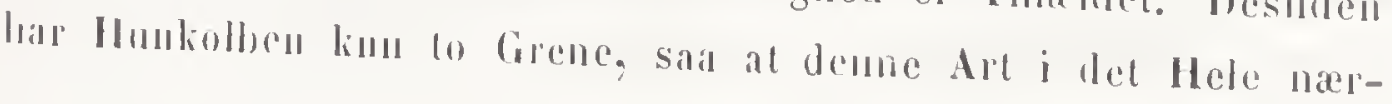


mer sig til Cliam. geonomaformis Wendl. og danner Overgang til Understagten Psilostachys.

Alle Arter, som med Sikkerhed kunne lienföres til denne Underslaegt, liave med Undagelse af ovenstaaende lijemme i Sylamerika, navnlig i Ny Granada; een Art er kjendt fra Bolivia.

C. (Eucham a edorea) pinnatifrons (Jacq.) - Borassus pinnatifrons Jacy. Hort. Schoenbr. 2. 65. 1. 247-248. - Chamacdorea gracilis (Willd.) Act. Ber. 1804.41. - 6-10' hïi. Bladene $4^{\prime}$ lange, 9 Par aflang- eller lancetdannet-rhombiske, lidt S-formigt krummede, tilspidsede Smaablade, som isaer loroven sidde tat sammen. Afstanden mellem de övre Bladpar er $\frac{1}{g}-1 "$,

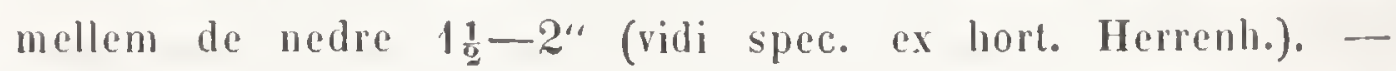
I Nierheden af Caracas, hvor den ogsaa er fundet af Dr. Karsten (Limmaca 20. 446).

C. (Euchamacdorea) lanceolata. (Ruiz et Pav.) Martinczia lanceolata Ruiz et Pay. Flor. per. 247. - Chamaedorea lanceolata Kunth Enum. 3. 172. - Martius Palm. Orbign. 4. 1. 6 f. 3. 1. 16 d. - Adskiller sig fra C. pinnatifrons ved entyndere og mere buglet Stamme, langere Bladstill, smallere Smaablade $0 \mathrm{~g}$ större Bar. D'Orbigny fandt den i Bolivia paa den istlige Skraaning af Cordilleren ved Cochabamba.

C. (Euchamacdorea) flavovirens Wendl. Index Palm. 60. - 6-7 Par Smablade, der nasten have samme Form som hos C. gracilis, men ere gulgrönne, bredere foroven, mere pludselig tilspidsede, og baade Smaabladparrene og de enkelte Smaablade ere meget liengere fjernede fra limanden. (Afstanden mellem hine niesten 2", mellem disse nasten 1"). Hankolloen 16" lang med 12-14, 9-10" lange, medhangende Grenc. Manblomsterne sidde meget tat, ku II 1" lange; det indre Blomsterdatkes Blade sammenhangende i Spidsen. Hunkolben 14" lang med 12, 4-5" lange, stive, oprette Grene. Hunblomsterne sidde lattere sammen end hos de andre Arter. Dens Hjem er msilikert, men antages at viere enten Sy Granada eller Centralamerilia (vidi spec, ex hort. Herrenl.). 
C. (Euchamaedorea) Barllingiana. Wendl. I. c. 60. - Staaer meget nær den foregaaende, men er uden Tvivl en

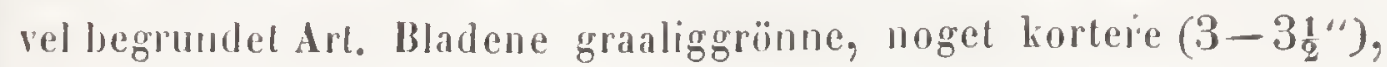
Smaabladene færre, 5 - 6 paa hver Side, parviis nærmere hinanden ( $\left.\frac{1}{4}-\frac{1}{2}{ }^{\prime \prime}\right)$, smallere, mere gradviis og langere tilspidsede, mere S-formig krummede, og Hovednerren gaaer foroven narmere ud mod Randen. De överste ved Grunden forenelle Smaablade ere meget længere $\left(10^{\prime \prime}\right)$. Hunkolben $20^{\prime \prime}$ lang; $6-8$ stive, oprette, 4, ¿ "lange Grene, gulgrönne ligesom Blomsterne. Disse ere mere fjermede fra hinanden end hos den foregaaende, fladere og mere nedsæukede $\mathrm{i}$ Gruberne. Det indre Blomsterdækkes Blade ere bredere, næsten nyredannede, Frugtknuden kortere og meget bredere ved Grunden. - Ny Granada. (v. spec. ex Hort. Herrenh.)

C. (Euchamacdorea?) brevifrons. Wendl. I. c. 61. Da Hunblomsterne ikke ere kjendte af denne Art, er det endnu trivlsomt om den hörer herlen. Bladene meget korte $22_{4}-2 !$. 6-8 Par Smaablade, parviis meget nær linanden; Afstanden mellem Parrene nxsten 1 $\mathbf{1}_{2}^{\prime \prime}$. De cre glindsende grönne, smallere end hos C. gracilis, længere tilspidsede og mere s-formigt krummede. Hankolben 12 "lang, med $9-12$ nedlangende 10 " lange Grene - Ny Granada.

\section{Subgenus 2. Chamaedoropsis Subg. n.}

Flores feminei e basi subrotunda globosi nec in scrobiculis imnersi. Perigonium exter. cupulare, trilobum. Perig. inter. foliola rolunda, ovarium amplectentia. Ovarium e basi angusta subglohosum, stigmatibus exsertis. Baccae saepius globosae. - Caudex gracilis rectus v. Iongissimus llexuosus subscandens. Folia pinnata; pinnae sacpius numerosac, angustae, rigidiusculac, basi callosae. Spadices inter folia perrumpentes.

Chamaedorea elatior Mart. (Linnæa 1830) og de med samme nar beslargtede Arter danue de mest typiske Former, som ligge (i) Crund for denne Underslagl, livis vasentligste Charakteer bestater $i$ den hugleformede Humblomst, som ikke er nedsanket i 
Kolloen og den kugleformede Frugtkunde. Flere af de Arter, som lı̈̈re lierlıen, cre imillertid endur sa mfuldstendig kjendte og lave en saa afrigende Habitus, at det maskee i Tiden vil hlive nödrendigt at lienföre dem til egne Undersliegler.

:) Legitima vel desmoncoidere.

Cauder saepius longissimus, flexuosus, ope pinnarum adscen dens. Folia longissima, ex orilicio vaginac refracto-dependenlia, vaginis longissimis cylindricis coriaceis clansis, peliolis brevissimis, pimnis numerosis lineari-lanceolalis rigillis plicalis longissime acuminalis, basi callosis reduplicalis, remolis allernis, sursum saepins decrescentilus opposilis deflexis, summis commalis laanateCormilus. Pedunculus lorevis.

Den meget lange; tynde og buglede Stamme, Bladene med moget store laederagtige Sheder, nasten nden Bladstilk, de lange smalle, stive Smablade (ved Grmuden forsynede med en lyh, haard Knude), som mod Enden af Bladet aftage gralriis i Störrelse ogr lilsidst omdannes lil bruskagtige nedadrendte Hager, der ljene til basthafung ba de omgivende 'Praer, give de lierlenhörende Arter et fra alle andre Chamaelorrer meget afrigende Udseende, som end mere foröges derved, at Bladstilken lige over Slieden er hrarket tilloage, sail at Blatdene hange red orer Stammen, maar de ilike red de laggeformede Smanhlades Tilhaduing lil andre Gjenstande holdes iveirel. Kullsestilken or hortere end Bladskederne, sia at Kolben mal giennenbryde skeden baale al det Blad, som unlspringer fra samme lacdinude, og af det, som sidder nedenumder. Hele Kíollestilken er salaledes omsluttet af Bbarlskederne, og limu Cirenenr. komme tilsyne.

C. (Cham a c doropsis) elatior. (Mart.) Limnar 1830. 205. - Chamachorea clatior Mart. Mist. Malm. pro parte. Wendl. Otto at Dide. Garten\% 1853. 181. - Chant. samdrus licbur. in Mart. Mist. Pillu. :3. 318.

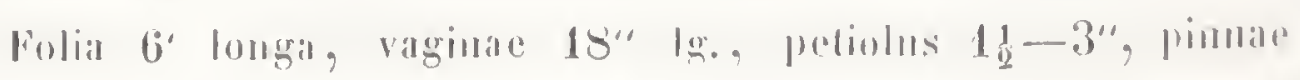
ulrinsecos 15-16, 3 inforiores anguslissimar approvimatar. median 
10' longa. Rami spadicis fem. 15-22, loasi patentes, dein erecti, 7-S" longi.

Deme Art blev allerede opdaget af Schiede i Mcxico 1829 og beskrevet af Martius i Linnaea; men hans Beskrivelse var saa ufuldstandig, at det er meget undskyldeligt, at Licbmann ikke har kunnet gjenkjende den, men beskrevet den som en ny Art under Navn af C. scandens. Efter Undersögelse af OriginalExcmplarer, som opbevares i det kongelige Herbarium i Berlin, og levende Plinter fra Haven i Herrenlausen har Wendland ansect det for sandsynligl, at den agte C. elatior falder sammen med Licbmanns C. scandens, hilket jeg nu ved nærmere Kjendskab til denne Art tör erklxre udenfor al Tvivl. - Den voxer i Östkystens Urskove imcllem 2-3000'.

C. (Chamacdoropsis) desmoncoides (Wendl.) Otto u. Dietr. I. c. 17\%. Ab antecedenti specie differt: petiolo breviore $(1-2 ")$, pinnis longioribus abruptius et longius acuminatis oppositis suboppositisve, spadice magis reflexo, ramis patentireflexis, floris fem. perig. inter. foliolis subrotundis apice levissime acuminatis, baccis majoribus (vidi spec. ex hort. Herrenh.).

C. (Chamaedoropsis) resinifera (Wendl.) l. c. 179. Affinis antecedenti, a qua tamen differt: foliis brevioribus (4--5'), petiolis nullis, pimnis minoribus, basilaribus $5-7$ multo minoribus valde approximatis, callo basilari longiore et angustiore, spadicibus masculis inferne dublicato-ramosissimis, fem. ramis erecto-appressis, foliolis perig. inter. latiorilous tenuioribus nervis pancioribus sed distinctioribus percursis, stigmatibus multo longioribus reflexis (vidi specim. ex lıort. Herrenh.). - Den !ıar ligesom deu foregalande lijemme i Mexico.

C. (Chamaedoropsis) affinis (Liebm.) - Chamaedorea affinis Licbm. in Mart. Hist. Palm. 3. 308. A tribus antecedentibus recedit: foliis brevioribus, pinnis multo minoribus tenuioribus callo minore instructis, omnibus alternis nec hamaeformibus ullis. Rami spadicis fem. It in C. resinifera crecto-subappressi; perig. 
iuterioris foliola subrotunda apice acuminata. - Lielımann fandt den i Chinantlas Bjergskove i en Höide af 3000'.

1) Anguste piniatac.

Caudex crectus. Folia maxima erecto-patentia, piunis numerosis approximatis lineari-lanceolatis.

C. (Chamacdoropsis) graminifolia (Wendl.) Ind. Pilln. 62.

Pinnac utrinsecus $36-42$, binac approximatac, inferiores suboppositac, patentes, lineari-lanceolatae, 10-12" longac, obsemre virides, flavesecntes, basis triangularis latere altero calloso, altero reduplicato subsaceato, nervo medio et duobus intramarginalihus prominulis. Spadicis masculi pedunculus 15-14" longus, ramis longissimis $\left(12^{\prime \prime}\right)$ pendulis. Flor. mase. lineam longi, ovati, densi. Perigon. cxterius minutissimum, virescens, interius vix stipitatum, lavescens, laciniis apice liberis (vidi specim. cx lort. IIerrenh.).

Den har af alle Chamedoreer de smalleste Blade og udmarker sig red Hankolbens meget lange Grenc, der nesten have samme Liengde som Kolbestilken, og ved det indre Blomsterdekke, der nasten mangler Stilk. Innplanten ukjendt Den antages at have hjemme i Centralamerilia.

C. (Chamacdoropsis) Karwinskiana (Wendlo) in Ottn et Dietr. Gartenz. 1853. 179. - Cham. elatior Mirt. in Otto et Dictr. 1. c. 1831. 216. - Ejusd. Hist. Palm. 3. 157 pro parte.

Candex 1S' et ultra longus, stoloniferus, nodis mediis 10-12" distantilus. Pinnac utrinsecus $27-33$, lincari-lanceolatae $1^{\prime} \lg ., 1 \frac{1}{4}-11^{\prime \prime}$ It., nervis secundariis utrinsecus $4-5$. Sparlix masc. $15-20 " \mathrm{lg}$., ramis $20-26$ pendulis $7-S^{\prime \prime}$ lg. Plores iis C. graminifolia similes, sed minus densi, perig. exterius multo majus, albescens, interius longius stipitatum. Spadix fem. $16-20$ " lg., ramis 18 patentilus 6 - g" lg. fructiferis lumenthus miniatis, baccis oblongis nigris (villi spee. ex hort. Herrenh.),

Wendland har vist, at deme Mel af Martius i Hist Palm. 
er heven forvexlet med C. elatior. Den har en ciendommelig IIabitus red Skud, som i Mangde skyde op fra Udlöbere. IBlomsterne ere gule og ildelugtende. Den har hjemme i Mexico.

C. (Chamacdoropsis) costaricanas sp.n. Folia clongatoovata, glaucescentia, $3{ }_{\underline{\alpha}}^{1}$ ' longa. Vagina? Petiolus $3{ }^{\prime \prime}$ Igg., trigonus, supra canaliculatus. Pinnac utrinsecus 18-20, elongatolanceolatac, acuminatae, inferiores 4 lineares, 6--7" log., aggregatac, proxima paria 3-4 opposita, ceterae alternantes aequidistantes, mediae 1'Ig., 12--14." It., basi contractae, nervo medio et utrinsecus duobus lateralibus prominulis flavescentibus, summac confluentes. Sparlix masc. $1^{\prime} \mathbf{4}^{\prime \prime} \mathrm{lg}$, simpliciter ramosus, pedunculus pedalis, crassus, compressus; spathae $5-6$, cylindricac, clausac; apice oblique aperlac, bifidac, albido-virescentes; rachis 7-S" longus, angulatus, curvatus; rami $24-26,6^{\prime \prime}$ longi, patentes. Flores in specim. meis nondum aperti.

Jeg fandt den j de fugtige Skove ved Turrialva paa Östsiden af Costa Rica $\left(3-4000^{\prime}\right)$. I Finnernes Form har den megen Lighed med C. macrospadix n., men er ellers meget forslijellig fra denne.

C. (Cli am a edoropsis) poclud lensis (Liebm.) - Mart.l. c. 3. 308. Cauder gracilis, elatus, dense annulatus. Pinnae numerosae, clongato-lanceolatae, acutac, $9^{\prime \prime} \lg ., 10-11^{\prime \prime \prime}$ tt. Spa-

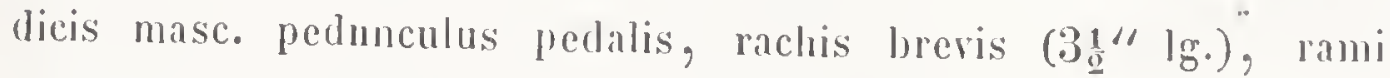
12-13 longissimi ( $\mathcal{L}^{\prime} \mathrm{lg}$ ) filiformes dellexo-penduli.

Voxer ifölge Liebmann i Urskovene paa Vestliysten af Mexico i Districtel Pochutla på $16^{\circ}$ I. Br. i en IIöide af 1200-1500'.

C. (Chama edoropsis) montana (Liebm.) Nart. I. c. 3. 303. Candex dense annulatus, abbreviatus. Pinnae numerosae, distantia $1 \frac{1}{2}-2$ " per paria approximatae, rigidae, plicatae, anguste lanceolatac, acutac, basi contraclic, callosae, $18-19 " \lg ., 1 " l t$. , summis conlluenlibus. Spadicis fem. pedunculus $S^{\prime \prime} \lg$., racluis angulata $2-2_{0}^{1} " \mathrm{gg}$, rami $10-11$ adrecto-patentes, coarctili, subfleruosi, 5" Ig. Perig. inter. foliola subreniformia. Baccae globosac, nigglac, 4"ll lougare. 
Spadice femineo, flore et fructu C. clatiori et C. affini valde similis, sed rachis unulto brevior, rami magis patentes curvatique. Ab hisce speciebus practerea caudice abbreviato et pinnis summis confluentibus recedit.

Licbmann fandt den i Bjergskovene $i$ de ïstlige Dele af Departementet Oajaca paa 2-3000' Höide.

C. (Chamacdoropsis?) macrospadix sp.n. Caudex in specim. jam fructiferis brevissimus, vix ullus. Folia elongatoobovata longepetiolata, erecto-patentia; vaginae sublignosac, clausae, fuscescentes, 7: Ig., inferne cylindricae, apicem versus postice compressiusculae, antice oblique apertac, auriculatae; petioli compresso-trigoni, supra canaliculati, 1' Ig.; rachis $2^{\prime}$ Ig., pinnac utrinsecus 10-12, alternac, anguste lanccolatac, acuminatac, basi contractac, plicatac, obscure virides, nervo medio valde obliquo et duobus intranarginalibus validis flavescentibus, secundariis utrinsecus 3 prominulis infimae 4 aggregatac, $7-8$ "longae, mediac

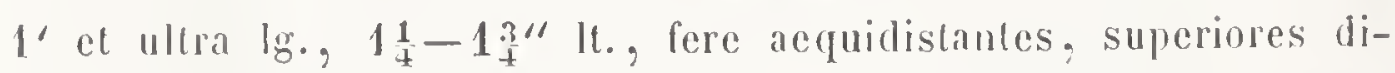
stantia 1-14" per paria approximatac, summac confluentes. Spadices masc. longissimi, subradicales, folia subaequantes; pedunculus $3^{\prime} \mathrm{lg}$, spatlate $6-.7$ fuscescentes, cylindricae, 10-12" longar, clausae, apice oblique apertae; rachis brevis $\left(3-4{ }^{\prime \prime}\right)$, subandula tus; rami 21-26, graciles, declinati, $S^{\prime \prime} \lg$., densiflori. Fores parri (l“" Ig.) subgglolısi, virescentes, perig. inter. foliola apice coarlunata.

Jeg fandt den i Turrialsas Bjergskove paa Östsiden af Costa Rica $\left(3-4000^{\prime}\right)$. De langstilliede Blade med et ilke stort Antal Fiuncr, som tilligened de uncoget langstilkede Kolber ulgaare fra en neppe syuliog Stamme, give denne Alt en frat alle andre Chat madoreer meget afvigende Halbitus.

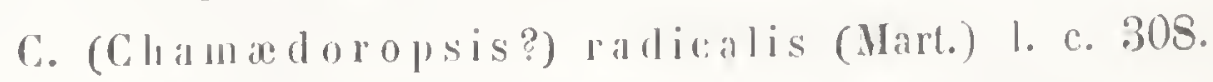

Denne Palmes nermeste Slargtskial) or endua hislsoml. Den a' forsynet med Udlöbere ligesom C. Karwinshiana, men har horte

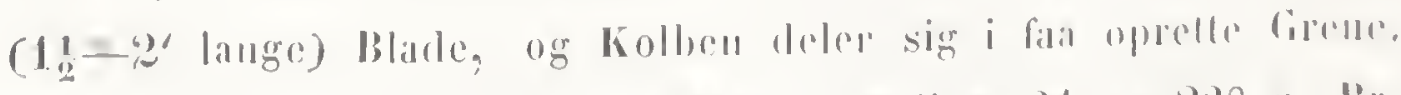

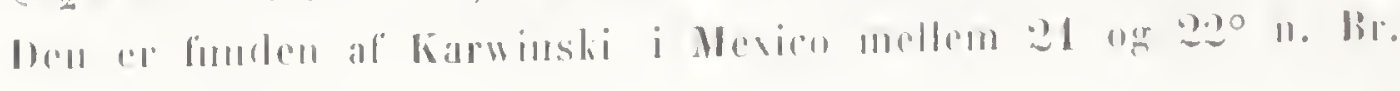


Tis) Aggregatae.

Caudex clatus $\left(12-15^{\prime}\right)$ crectus. Folia magna $\left(1-5^{\prime}\right)$ erceto-patentia, pinnis mumerosis clongato- $v$. lineari-lanceobatis in greges approximatis.

C. (Chamacdoropsis?) glaucifolia (Wendl.) Ind. Palur. 61. Pinnac utrinsecus 90-80 lineari-lanceolatac, $15-18 / 1 \mathrm{~g} .$, $3-4^{\prime \prime \prime ~ I l ., ~ 4-7 ~ i n ~ g r e g e s ~ i r r e g u l a r e s ~ a p p r o x i m a t a c . ~}$

Hanplanten dyrkes i den botaniske Have i Brüssel og anlages at have hjemme i Chiapas.

C. (Chama doropsis?) Klotzschiana (Wendl.) I. c. 63. Pinnac utrinsccus 15-- 18, clongato-lanccolatac, acuminatac, basi altero latere callosac, altero reduplicato-subsaccatae, mediae $1^{\prime} \mathrm{Ig}$. $1_{2}^{I} "$ lt., ternac in greges subopposilos approximatac (vidi spec. ex hort. Herrenh.). Den har hjemme i Mexico.

$$
\text { *xws) Late pinnatac. }
$$

Caudex crectus, clatus $\left(6-12^{\prime}\right)$. Folia mediocria $\left(2 \frac{1}{2}-3 \frac{1}{2}^{\prime}\right)$, crecto-palentia, pinnis paucioribus (utrinsecus 5-12) trapezoidcis v. elongato-oblongis subsigmoideo-curvatis.

Cliam. lunala danner Typus for denne Afdeling, som ved faa og brede Finner slutter sig narmest til Euchamacdorea.

†) florilus mase. oblongis, perig. inter. foliolis apice liberis.

C. (Cliama edoropsis) lunata (Licbm.) Mart. I. c. 3. 307. Pimne utrinsccus 6 oblongo-trapczoideac, summis confluentibus. Pedunculus spadicis masc. ferme pedalis, rachis $4^{\prime \prime}$ Ig.; rami 1j-16, declinato-penduli, S"Ig.; perig.inter. siccalione nigrescens.

Lichmann fandt den i Urskoren langs Mexicos Östkyst imellem $20-21^{\circ}$ n. Br., paa 500'-1200' llöide.

tf) floribus masculis subglobosis, foliolis perigg. inter. apice coadunatis.

C. (Chama cdoropsis) Lindeniana (Wendl.) in Ollo et Dictr. I. c. 1853. 139. Pinnac utrinsccus à oblongo-trapczoideac, mediac $10-11^{\prime \prime} \mathrm{lg} ., 4-4,5 " \mathrm{lt}$., infimae 3 approximatae reflexopatentes, summis late confluculibus. Pedunculus spadicis fem. 14-15" Ig., rachis 3-4", rami 15-20 adrecti, graciles, angulati, leviter llexuosi, apice nudi. Flores minutissimi (1"' Ig.) 
llarescenti-virides hasi in scrobiculis subimmersi. Foliola perig. inter. rotundo-ovala (vidi spec. ex lort. Herrenls.).

Den ligner i Bladene C.lunata, men den har farre og meget bredere Finner. Stammer fra Mexico.

C. (Chamaedoropsis) Schiedeana (Mart.) in Limnea 1530. 204. Folia longe petiolata, pinnis utrinsecus 10-12, late lanceolatis, binis approximatis, superioribus oppositis, summis confluentibus. Spadicis masc. rami numerosi longissmi curratoadrecti, fem. 12-15 tenues, inferiores patentes, superiores adrecti.

En af de tidligst kjendte og mest almindelig udbredte Arter. Voxer i Mexico og den nordlige Deel af Centralamerilia, fra $14-22^{\circ}$ n. B. paа $500-3000^{\prime}$ Höide.

Cha maedorea concolor Mart. (I. c. 3. 160) synes, saavidt man kan slutte af den meget korte Beslirivelse, ogsaa at höre til denne Afdeling og at vare narmest beslagtel med $C$. lunata og Iindeniana.

*****) Confluentes.

Caudex gracillimus, humilis, procumbens, dense annulitus. Folia parva tencra, pinnis in dimidia parte superiore racheos in laminam bifidam confluentes.

C. (Chamaedoropsis) membranacea sp.n. Caudex in specim. jam fructiferis pedalis, procumbens, inferne radicans, $3^{\prime \prime}$ flametro, nodis $\frac{1}{2} "$ distantibus. Folia longe petiolata, tenuissime menbranacea, laete viridia, 1!' longa; vaginae $\mathbf{4}^{\prime \prime}$ lg., cylindricae, clausae, apice oblique apertae; petioli tenuissimi, compresso-trigoni, 5 "Ig., supra leviter canaliculati; pimat utrinsecus $6-\%$, inferiores 6 linae approximatae, suboppositac, aequales, lanccolatae, falcatae, Ionge acuminatae, 5-6"lg., 9-10"' lt., nervis 4: aequidistantilus validiorilous percursae, superiores $6-8$ in laminam terminalem nervis circiter 20 percursam apice bitidam, altero latere saepius iaregulariter pinnatifidam conflucules. Spadix fem. S"lg., infra coman cuatus; pedunculus $5^{\prime \prime} \lg$. inferne compressus, spathis, ut videtur, 5 (in specim. meis jim ferme de- 
lapsis) fuscescentibus techus; rachis $1 \frac{1}{2}-20$ lg., angulata; rami b, adrecti, 2010 lg. Flores remotiusculi, nigrescentes, perig. exter. lobis (sub fruclu) undulalo-reflexis, interioris foliolis subrolundis concavis, ventrali ceteris fere duplo minore. Bacea oblique oblonga, nigra, 4-5" ${ }^{\prime \prime}$., Jasi stigmatibus coronata, pericarpio tenui sicco rugoso nilido, semine orato, cmbryone in medio dorso.

Jeg fandt denue lille Palme, som red Bladenes form og Tyudlued er meget afrigende fra alle Clamindoreer, i de yppige Bjergstiove pa Pantasmo i Provindsen Segovia pad den nordligste Grandse af Nicaragua, med Frugt i Januar.

\section{Subgenus 3. Chamaedorella $n$.}

Plores feminei ovati nec in scrobiculis immersi. Perigonimn exterius virescens, cupulare, trilobum; interioris flavescentis foliolis ovata, laxa. Ovarium obovatum, stigmatibus inclusis. Bacca? - Caudex crectus. Folia pinnata crecto-patentia, Icpidibus minimis obsita, glaucescentia, pimnis clongato-lanceolatis, summis conllucutibus. Spadices infa comam patentes, masculi simpliciter ramosi, ramis mumerosis pendulis, feminci duplicato-ramosi, rimis tenuissimis patentibus.

Denne Underslaggt er vasentlig forskjellig fra de foregaacude red Humblomsternes agformede gule indre Blomslerdaklic og ved Ilunkolbens meget tyude declte Grenc, lworved den farer megen Lighed med Collinia; men denue har et tredectt indre Bblonsterdakke og klappet Knopleic. Hos den cneste herhenliörende Art have bladene en graalig farre og ere behledte med meget sma tatle Slijed.

C. (Cliamacdorella) Icpidota (Wendl.) in Ollo el Dictr. I. c. 1553.139 (vidi spec. ex lort. Herreul.).

I Bladenc har den nogen lighed med C. Schiedeana. Den er indfört i de Jelgiske IIaver, lvor den tidligere dyrkedes under Nave af C. relulima. Ifölge Galcolli stammer den fra Mexico og ifölge Limden fra Ny Granada, men det er ilike rimeligt, at den har hijemme begge Steder. 


\section{Subgenus 4. Psilostachys n.}

Flores flavescentes, maseuli femineis $2-3$ plo majores. 11 i depresso-globosi, in scrobiculis subimmersi. Perig. exter. fere triphyllum interius subaequans, hujus foliola rotunda, concava, ovalium arete amplectentia. Staninum rudimenta minulissima. Ovarium obovaturn; stigmata minutissima, erecta, exscrta. Bacea? Flores mase. compresso-globosi. Perig. exter. minutissimum, membranaceum, anuuliforme, trilobum, lobis brevissimis latissimis, inter. breviter stipitatum, foliolis apice coadumatis. Antherarum loeuli conjuncti. Caudex erectus, gracilis, dense annulatus. Folia ereeto-patentia, simplicia, obovata, apice fureati, vaginis brevibus ovato-oblongis apertis, petiolis brevissimis. Spadices inter $r$. infra coman enali, adrecti, longe pedunculati; masc. 4-6ramosi, ramis densilloris pendulis; fem. simplices $v$. 2-3ramosi, ramis geminis ternisve carnosis elongatis erectis curvatis.

Denne Underslegt staaer med Hensyn til Itunblomsternes Form midt imellem Euchamaedorea og Chamaedoropsis, men er i Bladene og Blomsterstanden meget forskjellig fra begge.

C. (Psilostachys) geonomaeformis (Wendl.) - Chamaedorea geonomaeformis Wendl. Otto el Dietr. 1. c. 1852.

Denne smukke lille Palme blev indfört af Warseewicz fra Guatemala i det Van IIoutteske Etablissement. Exemplater fra den kongelige Have i Herrenhausen ved Hannover have blomstrel i vor botaniske Ilave.

\section{Sulogenus 5. Rummezharia Ruiz et Pav.}

Flores flavesecntes, masc, et fem. aequales. Hi globosi nee inmersi. perig. exter. cupuliforme tripartitum, inter. triphyllum, foliolis suborlucularibus. Staminum rudimentum nullum. Oralrium ovato-globosum, stigmala revoluta. Flores masc. glohosi. perig. exter. cupuliforme virescens tripartilum, tobis rolundatis, inter. obovato-globosum vix stipitalum, foliolis apice liberis. Antherarum loculi sejuncti, basi ef presertim apice diergentes. 
Candex erectus gracilis. Folia simplicia, furcalo-bipartita, raginis cylindricis clausis. Spadices masc. et fem. aequales, breviter pedunculati, ramosi, ramis paucis adrectis curratis (vidi flor. mase. in herb. Hort. Hafı. a cl. Martio miss.).

Nunnezharia slutter sig vel i det flele temmelig nacr til den foregaacnde Underslægt, men er dog meget vel sondret fra denne haade ved Blomstens Bygning og ved sin Habitus. Hanblomsterne ere isar meget forskjellige red Stöknappernes Form og ved et stort dybt deelt ydre Blomsterdicke. Han- og Hunkolberue ere mere censtannede cud hos alle andre Chamedoreer og have samme Antal korte, opstaaende, krummede Grene. Bladskederne ere eylindriske og lukikede. Iferhen hörer kun een Art, som af Ruiz og Pavon henförtes til en egen Slægt, men af Martius blev forenet med Chamaedorea.

C. (Nunnezharia) fragrans (Ruiz. et Pav.) Chamaedorea fragrans Mart. I. c. 2. 4. 1. 3. Nunnezharia fragrans Ruiz. el Pav. Prodr. flor, per. el ehil. 13\%. t. 31.

Stammen $4-6^{\prime}$ höi. Den har bjemme i Peru.

\section{Dasystachys g. $\mathrm{g}$.}

\section{Stachyophorbe Klotzsch sed non Liebm.}

Flores hexagoni densissime congesti. Mase. Perig. exter. membranaceum albidum annuliformi-trilobum, interioris foliola carnosula atroviridia, concaviuscula, dorso compressa, apice depresso-plana conniventia, praefloratione valvata. Filamenta plana; antherae minutae, introrsac, dorso affixae, oblique incumbentes. Fem. Perig. exter. cupulare, membranaceum, albidum, interius alte amplectens, irregulariter multilobum; interioris foliola subreniformia, concara, compressotrigona, apice carnosa depressa, duobus exterioribus, tertio interiore et subcymbaeformi, pracfloratione convoluto-imbricata. Staminodia 5-6 inaequalia. Ovarium clongato-ovatum, subtrigonum, apice attenuatum; stigmata tria reflexa, longe exserta. - Caudex crectus, abheviatus, dense anmulatus. Folia simplicia, erectopatentia, bifido-furcata, vaginis clausis. Spadices simplices, 
erecti, longius pedunculali, solitarii, bini v. terni, infra v. iuter folia enati. Flores octoseriatim orti, in racheos scrobiculis densissime congesti.

Denne Slagt slutter sig narmest til Stephanostachys, med luvilken den stemmer overcens i Hanblomstens indre stilklöse Blomsterdakke, i Stïrknappernes Form og de tetsiddende Blomster, men er forresten meget forskjellig baade ved Blomsternes form og ved sin Habitus. Den eneste bekjendte Arl blev af Klotzsclı henfört til Stachyophorbe L.bm,, en Feiltagelsc, som paa Grund af den meget korte og tildeels urigtige Beskrivelse af denne Slagt var meget undskyldelig. Dasystachys og Stachyophorbe kunne betragtes som analoge Slagter af to forslijellige Grupper; hiin staaer i samme Forhold til Stephanolachys, som denne til Chamacdorea.

D. Deckeriana (Kil.). - Stachyophorbe Deckeriana Kil. in Otto el Dietr. I. c. 363. - Caudex 3-4' longus, 1" diametro. Folia 2 'longa. Spadix fem. 15", masc. 6" longus (vidi spec. ex hort. Herrenli.).

Den er indfört 1849 af Warscewicz fra Guatemala oor blomstrede fürste Gang i Over-IIofbogtrykler Deckers store Palmehuus i Berlin (1Sอ2).

\section{Strphanostachys Kl.}

Flores masc. telragoni, depressi v. subglobosi. Perigonium cxtcrius minutissimum v. fere evanescens, amnuliforme tridtentatum v. ferme triphyllum, tenuissime inembranaceum, laciniis lincaribus excisuris maximis inter se remotis. Perig. inter. tetragono-globosum, depressum, triphyllum, foliolis subcarnosis concavis medio dorso incrassatis subcompressis conniventibus, pracfloratione valvatis v. suluvalvatis. Autherac introrsac, dorso alfixac, oblique incumbentes. Flor. fem. depresso-globosi. Perig. exter. profunde tripartitum, inter. triphyllum, foliolis rolundatis concaviusculis ovarium laxe amplectentibus, praflorationc convoluto-imbricatis. Ovarium subglobosum, stigmata rellexa. - 
Caudex abbreviatus, deuse ammulatus, interdum dichotomo-partitus. Folia pinnata, vaginis cylindricis clausis apice oblique apertis, pinnis mumerosis anguste lanceolatis falcatis $v$. linearibus longe acuminatis nervis validis percursis. Spadiees breviter pedunculati, simpliciter ramosi, densiflori, spathis viresecntibus laxe vaginantibus, mase. multiramosi, ramis pendulis, fem. pauciramosi, ramis erecti.

Klotzsch betragter Steplianostachys som en Underslagt af Chamacdorea, men denne udmarkede Botaniker er ikke bleven opmarksom paa flere Forhold i Blomstens Bygning; hvorved saavel den Art, hrorpa han grundede sin Underslegt, som de Arter, der senere ere blevne henförte til denne, adskille sig saa væsentlig fra Chamacdorea, at selv deBotanikere, som give Slægterne en mere udvidet Begræendsuing end jeg anseer for rigtig, ikke vilde lunne henföre disse Planter til samme Slagt. Hanblomstens ydre Blomsterdakke er nemlig saa lille, at det kun opdages red en omhyrgoclig Undersögelse, eller det bestaaer af tre meget tynde, red store Udskjaringer adskilte, nasten frie Blade, og dens indre Blomsterdakke er stilklöst. Desuden ere de lierhenhörende Arter meget forskjellige fra Clamaedorea ved IIunblomstens Form og i deres liele Habilus. Stammen er lar og bestaace af korte Led, Smaabladene oftest store med slarkt fremtrædende Aarer, Blomsterne sidde meget tat, navnlig Hanblomsterne, saa at disse ved det gjensidige Tryk blive kantede, og den korte Kolbestilk er omgiven af store, grönlige, löst omsluttende llylsterblade. S. Casperiana er saa afvigende fra de andre Arter i IIanblomstens Bygning, at det vistnok vilde vere rigtigst at henföre den til en egen Underslagt, om ikke Slagt; men da jeg kun lijender Manplanten, lar jeg ikle villet foretage nogen Sondring.

*) Florum masc perigonium exterius fere triphyllum, lacinis linearibus albidis perigonim interius subaequantibus.

Steplianostacliys Casperiana (Kl.). - Chamacdorea (Stephanostachys) Casperiana Kl. in Otto et Dietr. 1. c. 1852. 363 (vidi spee. mase. ex hort. II errenh.). 
Demue Art er kun kjendt af dyrkede Exemplarer, opliomne af Frö, som vare samlede i Gualemala af Warscewicz.

***) Florum masc perigonium exterius minutissimum, evanescens, annuliforme, tridentatum.

Stephanostachys Wendlandiana sp. n.

Chamaedorea Tepejilote Wendl. Ind. palm.65. -- Folia 4'longa; petiolus pedalis supra inferne canaliculatus dorso fascia albida notatus. Pinne utrinsecus 18-20, anguste lanceolatac, longe acuminalac, leviter falcatac, mediac $20 " \mathrm{lg} ., 1 \frac{1}{2} " \prime$ et ultra lt., alternac, binac approximatae, inferiores suboppositae, fusco-maculatac, siccac fragiles, nervis 7 validis percursac. Spadix masc. 11/' Ig. Pedunculus pedalis gracilis, subteres, curvatus. Spathac 7 laxac, chartaceac, virescentes, striatac; quinta et scxta a basi $10^{\prime \prime}$ Ig., supernc dilatatac, ad medium clausac, apice acuminatac, septima sexto multo minor apice truncata. Rami numerosi (20-2.j), 6" Ig. Flores densissime sexseriatim orti, favescenti-virides. Spadix fem. 10"lg.; rami $6-7$ erecti v. adrecto-patentes, $3 " \lg$. flores densissime sexseriatim dispositi, in scrobiculis immersi.

Affuis S. Tepejilote lichm., a qua differt: ramis spad. masc. multo numerosioribus, horibus scxscriatim dispositis, dentihus perigonii cxler. longioribus, interioris foliolis obtusioribus.

Demue Art dyrkes i det store Palmehuus i den kougelige IIave ved IIcrenlausen, livorfra jeg ved Herr Wendlands lionekommenlued har fiact törrede lixemplarer under Nave af Chamacdorea Tepejilote liebm.

steplianostaclus Tepejilote (Lichm.) - Clamacdorea Teprojilote Jicbur. in Mart. 1. c. 3. 303.

Liebmam fandt den $i$ bunden af de dybe Baranliel par

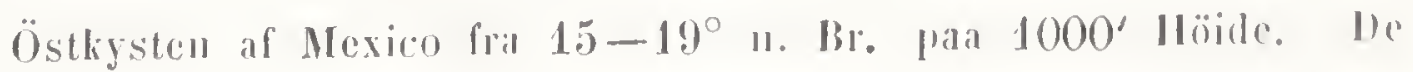

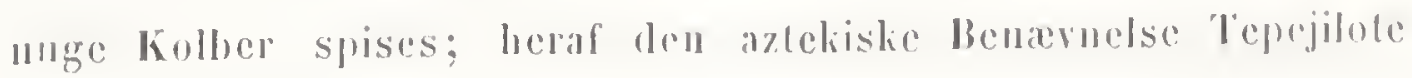
(ว: cerebrum plantac montanac). 
Stephanostachys Martiana (Wendl.). - Chamacdorea (Stephanostachys) Martiana Wendl. in Olto et Dietr. 1. c. 185.3. 137 (vidi spec. ex hort. Merrenh.).

Habitu a ceteris valde recedit, caudex cnin, ut videtur repens, dichotomo-partilus est, et folii longepetiolali pinnae multo minores, lincares.

Den antages at hare hjemme i Mexico, men er kun kjendt af dyrlede Exemplarer.

\section{Spathoseaphe g. n.*)}

\section{Slephanostachyis spec. Wendl.}

Flores masc. oblongo-obovati hasi compressi. Perigon. exter. breviter tubulosum, leviter trilobum, membranaceum; interius obovalum basi compressum, cum filamentis et pistillo rudimentario in stipitem solidum connatum, laciniis oblongis vix concavis. Antherac introrsae, dorso affixac, oblique incumhentes. Flor. fem.? - Caudex ereclus remote annulatus. Folia maxima, pinnata, raginis longissimis cylindricis apicc oblique apertis, pinnis elongato-oblongis remotis longe acuminalis. Spadices infra comam enali, brevissine pedunculati, densillori; masc. subumbellatim ramosi, ramis simplicibus pendulis: fem. simplices r. pauciramosi, erecti, crassi. Spathae coriaceo-chartaceac, compressac, ad basin pedunculi confertac, summa congalo-cymbacformis, accuminata, dorso applanata, ventre aperta.

Denne Slagt alskiller sig vasentlig fra den foregaacnde red Hanblomsterne, som lave et rördannet, trelappet ydre Blomsterdieklie og et stilket indre Blomsterdaklie med nasten flade, allange Flige. Desuden er den meget forslijellig i ITabitus, red lange Stiongelled, brede Smabblade og navnlig ved Hylsterbladene, som sidde tat samlede ved Grmolen af Kolbestillien, og af hrilke det överste er stort, baaddannet og aahner sig paa den indrendige Side, og endelig ved den kortslilliede Kolbe, som

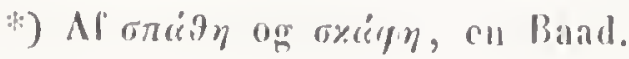


gjennembryder Midten af Hylsterbladene og hos Hanplanten er skjarmformig forgrenel, men oftest enlielt hos Hunplanten.

Spathoscaphe Arenbergiana (Wendl.). - Chamaedorea (Stephanostachys) Arenbergiana Wendl. Index palm. 66 (v. spec. ex hortu IJerrenh.).

Denne Art er kun kjendt af dyrkede Exemplarer, men anlages at have hijemme i Centralamerika.

\section{Iriartea Ruiz et Pav.}

Iriartea durissima sp. n.

Caudex rectus, strictus, $100-150$ pedes altus, diametro $S-10$ pollicum, lacrigatus, annulatus, cinerascens, radicibus extraterraneis brumneis verrucosis $6-10$ pedes longis suffultus. Corpus ligneum durissimum, gravissimum et eximic firmum. Folia longissima, multijuga, vaginis sexpedalibus in cylindrum viridem apicem caudicis coronantem convolutis, vento agitante phalerum amoenissime fluctuantem exhibentia. Pinnac alternae, herbaceac, glaucescentes, siccae fragiles, glabrae, elongato-oblongae v. irregulariter rhombeac, apice et margine superiore repando-erosac, nervis $15-16$ parallelis prominentibus percursae, ferme 2 pedes longae, medio $4 \frac{1}{y}$ poll. latae; basi contractac, 1 polt. latae, fusco-tomentosac. Inflorescentia mihi ignola. - Ab Iriartea pracmorsa, cui maxime affinis, distinguitur pinnarum forma et magnitudine.

Denne smulke Palme er hyppig i Urskoven, som grjennemskjæres af Floden San Juan i Nicaragua, hror den paa mange Steder med sin yndige Kirone laiger höit op over de andre Sliortrxer. Den berer blandt Landets Indraanere Navn af Maquenque og udmarker sig ved overordentlig lıardt Ved. Det er den eneste Art af Slegten Iriartea, som hidtil er funden nord for Panamatangen.

\section{Euterpe Gaertn.}

Martius angiver som Slaglscharaliteer ef trehlatet yolir Blomsterdakke hos Hanblomsten, men hos de to Mrter, som beskrires 
nedenfor, maa det snarere kaldes sambladet tredect, og del samme synes ogsaa at gjælde om de andre Arter ifölge de nöiagtige Analyser af Blomsterne i det store Palmevark. Ligeledes frembyde Stövdragerne et Forhold, som hidtil er bleven oversect, idet den üverste Decl af Stövtraaden er meget tynd og i Knopleiet tilbageböict.

Euterpe macrospadix sp. n.:

foliis brevipetiolatis, pinnis utrinsecus $35-10$, binis approximatis suboppositis, longissimis lincaribus punctis elevatis adspersis in rachim leviter decurrentibus, spatha interiore cylindrica coriacea utrinque attenuata fusco-tomentosa, spadicis pedunculo crasso compresso ramis 2-3plo breviore, ramis numerosis sub anthesi creclis foribusque pube brevi conspersis, bracteolis $3-4$ minutis membranaccis circa basin floris fem. in orbem dispositis, exteriore minutissimo et quasi nihil nisi margo scrobiculi pro flore feminco exsculpti, duobus v. tribus interioribus paulo majoribus triangularibus, flor. masc. perigon. cxter. laciniis albidis triangularibus concavis aculis margine scariosa sibi imbricatis carinatis dorso basi callosis, perig. interioris foliolis oblique ovatis acutiusculis, floribus fem. globosis, ovario ovato-globoso stipitato, stigmatibus vix conspicuis. Caudex erectus $50-80$ pedes altus. Folia $7-8$ pedes longa. Rachis subtetragona, 5-6" diametro, subtus convexo-scmiteres tomento fusco detergibili tecta, supra bifacialis. Pinnae mediac 2 'longac, 1" latac, siccac glaucescentes, subplicatac, nervis primariis intrinsecus 5 prominentibus. Spatla interior fere tripedalis. Pedunculus 8 "lg., $8-10^{\prime \prime}$ diametro, basi semicirculari $2^{\prime \prime}$ lata caudici insidens. Rachis $10 "$ lg. Rani sesquipedales. Affinis E. cduli, a qua differt pinnis multo paucioribus, spatlace interioris forma et vestimento, pedunculo multo longiore, bracteolarum florumque omnibus partibus diversis.

Voxer i den talte Urskov ved Floden San Juan i Nicaragua i Nierheden af Sarapiqui, livor jeg fandt den med Blomst i 
Euterpe longepetiolata sp. n.:

foliis longissime petiolatis, petiolo et raclii dorso tomento fusco detergibili tectis, pinnis utrinsecus 20-25 alternis, hinis approximatis, inferioribus ferme oppositis, lineari-lanceolatis acumine longo tenui terminatis, chartaceis, rigidis, supra fuscescentibus nervo medio valido elevato, subtus pallidis nervis lateralibus primariis utrinsccus 4 percursis, inflorescentia longissima tenui tomento brevi fusco detergibili tecta, spatha interiore coriacea clausa cylindrica, aperta lineari-lanceolata basi vaginante apice acumine tereti terminata glabrata fuscopunctata, pedunculo longissimo tenui tereti, ramis 8-12 arrectis rachi 2-3plo longioribus, bracteolis tribus minutissimis membranaceis subaequalibus circa basin floris feminei in orbem dispositis, altera exteriore duos interiores amplectente, foris masc. perigonio exteriore basi obliquo, laciniis triangularibus acutis carinato-concaris, margine sibi imbricatis, perig. interioris foliolis coriaceis leviter striatis suboblique ovatis acutiusculis, floribus femin. subglobosis acutiusculis, ovario clarato, sligmatibus vix conspicuis.

Folia 8-9'longa. Vaginae cylindrica, fuscae, apice oblique apertae. Petioli teretes, subtrigoni, 2-3' longi. Pimac 1, $1,-2^{\prime}$ Ig., fere $1 \frac{1}{2} "$ It. Spathae $2 \frac{1}{2}$ 'Ig., apertac medio 1" 11 . Pedun-

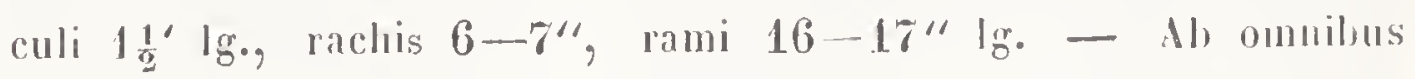
specielus adhuc notis omuibus partibus fuscescentibus, peliolis pedunculisque et spathis longissimis primo intuitu facite distingruitur.

Jeg fandt den pala den östlige Heldning af Cordilleren i Costa Rica i Nerlueden af Turrialsa i en Höide af henved 3000 fod, med Blomst i Mai. Den benwues af Landets Bebocre Pacaya Ratoll.

\section{deromoma Willd.}

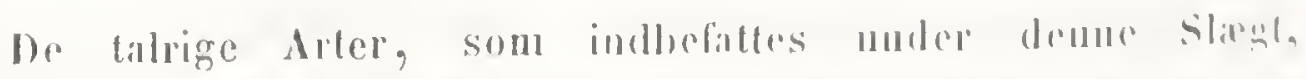
vise sala store Forskjebligheder baade i Blomstems Baguing nug 
i IIabitus, at det vistnok vilde vare rigligst al fordele dem i flere Slagter, eller idetmindste i flere Underslagter. Jeg lıar imidlertid ikke lavt tilstrakkeligt Materiale til Undersögelse (i) at jeg for Tiden lör foreslaac nogen Forandring; men jeg skal kun bemarke, at enkelte viglige Forlold ved Blomsten ere bleve oversele af lidligere Forfatlere, lwilket saa meget lettere kunde skee, da Blomsterne lios de fleste Arter ere meget sma og tildecls ligge skjulte i Gruber. De fleste Arter lave saaledes to rudimentiere Hanblomster i lover Grube ved Siden af den fruglbare IIunblomst, et Forlıold, som ikke omlales af Martius, men som fürst er blevet udlared af Wendland ${ }^{*}$ ), og desuden lıar jeg loos alle de Arter, jeg lar undersögl, fundel $1-3$ smaa Deliblade, Jwilke Organer ikke lidligere ere blevne iagtlagne hos denne Slagt.

a) Spadicibus duplicato-ramosissimis.

Geonoma binervia sp. n.:

foliis pinnatis, pimnis utrinsecus $18-19$ subopposilis lineariJanceolatis falcatis acuminatis glaucescentibus rigidis supra binerviis, superioribus alternatim latioribus et angustioribus, summis confluentilus, spadicibus maximis duplicato-ramosissimis, ramulis gracilibus fuscis tepidoto-luisulis, foveolis margine inferiore bifidis, stylo longius exserto.

Caudex clatus, annulitus. Folia 4-5' longa; racluis glabra, uilida, supra bifacialis, ad latera sulcata, sulutus convexa; pinnae mediac $15-16^{\prime \prime}$ longac, vix pollicem latae, supra nerris duobus robustioribus percursac, sublus nerro medio el duolıs marginalibus prominentibus, sccundariis utrinsecus 3 prominulis. Spadix femineus $2 \frac{1}{2}{ }^{\prime}$ Iongus; pedunculus communis lıasi semilunari affixus, compressus, $S-10^{\prime \prime}$ crassus, glabralus; rachis flexuosa; rami primarii crassi, basi lala raclem amplectentes, bractea lata brevissima semiamplexicauli suffulti, curvati, pa-

*) Jimmaea 1856, p. 334 . 
tentes, 11: longi, pars inferior ramulis carens semipedalis; ramuli floriferi teretiusculi, patentes subflexuosi, fuscescentes lepidoto-hirtuli, $4-4 \frac{1}{\frac{1}{2}}$ ' longi, apice mucronati. Flores in quari fovea terni, bracteola minutissima subrotunda suffulti, medio fructifero, duobus lateralibus minutissimis rudimentariis. Foliola perigonii exterioris sublanceolata, carinato-concara, margine tenuissime membranacea, nitida, inaequalia, duobus posticis obliquis. Perigonium interius exteriori paulo superans, trifidum laciniis acutiusculis pallidioribus. Urceolus staminum abortivorum cylindricus, leviter denticulatus, olsscurus, aeque ac stylus exsertus. Stigmata tria recurva. Bacca immatura oblonga, utrinque acula, nigrescens.

Denne Art stemmer narmest overeens med G. multiflora og Pohliana, men er dog resentlig forskjellig fra begge. Den har af alle bekjendte Arter den störste Blomsterstand og er let kjendelig ved to stærkt fremragende Aarer paa Overfladen af Finnerne. - Jeg fandt den i den Latte Urskor ved Bredderne af Flodeu San Juan, med Blomst og umodne Frugter i Fobruar.

- (wa) Spadicibus simpliciter ramosis.
Geonoma trifurcata sp. n.:

tota fuscescens, foliis obovato-lanceolatis basi-cuneatis apice bifidis, tandem irregulariter pinnato-fissis, laciniis oblongis nonnilil introrsum falcatis acuminatis, rachi supra inferne excavala grabra nitidula, dein acute bifacialis, subtus consera tomento fusco detergilsili tecta, pedunculo gracili compresso fusco rigido, spadice trifurcato, ramis aequalibus teretibus apice mucronalis rectis vel curratis, lateralibus patentibus, alveolorum labio inferiore integro revoluto, baccis (vis maturis) ollique oblongis subcompressis utrinque acutis fuscis striatis.

Folii lamina $2 \frac{1}{2}-3^{\prime}$ longil, 6-S" lata, percursa linearum $1 \frac{1}{2}$ distantia nervis primariis parallelis, quorum alterni sulutus solummodo prominent supra suleum tantem exhibentes, merro secumdario utrinsecens 1 subtus prominnlo smpra vis comspieno: 
laciniac $9-10^{\prime \prime}$ longae, basi $3 \frac{1}{2} "$ latae. Petioli speciminibus meis desunt. Pedunculi $1 \frac{1}{2}$ longi, $1 \frac{1}{2} " \prime$ diametro. Spadicis rami $5-6 "$ longi, fuscescentes, subalutacei. Baccae vix maturae $4-5$ ”" longac. - Foliorum forma ad G. Spixianam proxime accedit, ab omnibus speciebus adluc notis spadice trifurcata distincta.

Voxer samme Sted som den foregaaende Art, lwor jeg fandt den masten afblomstret og med umodne Frugter i Februar.

\section{***) Spadicibus simplicibus.}

G e o n oma gla uca sp. n.:

foliis obovato-oblongis apice bifidis basi oblique cuneatis, tandem paenc regulariter pinnato-fissis, glauco-viridibus punctis elevatis minulissimis adspersis, laciniis utrinsecus $2-3$ lanceolatis longissime acuminatis, raclıi supra basi cxcavata dein acule bifaciali leviter flexuosa subtus convexa tomento fusco detergibili lecta, spadice simplici longissime pedunculato, pedunculo compresso glabrato, rachi subpedali tereli fuscescente alutacea subsigmoideocurvata mucrone Jrevi terminata, alveolorum labio inferiore semicirculari erecto emarginato-bilobo.

Folia $4-5^{\prime}$ longa; petioli pedales et vaginae fuscae; lamina $3-3 \frac{1}{g}$ 'longa, L' el ultra lata; distantia inter lacinias demum $2-3$ '. Nervi primarii distantia 4 linearum prominentes supra decurrunt, nervis secundariis vix conspicuis, subtus vero praeter nervos primarios llavescentes elianı secundarii utrinsecus 3 , quorum medius er duabus lineolis constans tomento levissimo sub lente conspicuo hinc inde conspersus est, prominent. Pedunculus 2-3' longus. Flores in alveolis racheos immersi, solitirii, obovati, ventre convexi, dorso concaviusculi, bracteolis tribus irregnlaribus minutissimis suffulti, in speciminibus meis non plane evolutis. Perigonii exterioris florum fem. foliola oblonga, carinatoconcava, acuta, albida, apice fusca, nitida, margine tenerrima, duobus lateralibns obliquis tertiun fere omnino obtegentibus. Perigonium interius tripartitum, laciniis ollongis acutis. - Inter species spadicilus simplicibus instructas foliorum laciniis glaucis 
Iongissime acuminatis distiucta G. Poiteanac imprimis spadicis longitudiue similis est, a qua vero practer alias notas absentia pilorum in raclii diflert.

Jeg har fundet den paa samme Sted som den foregaacnde, med Blomst i Feloruar.

Species incerlae sedis.

$$
\text { Geonoma longepeliolata n. sp. }
$$

Candex 4-5’alus, gracilis, annulalus, ligno durissimo, cortice gialno flavescente. Internodia inferiora $2^{\prime \prime I o n g a, ~ S " ' ~ d i a m e t r o . ~ F o l i a ~}$ longissime peliolata, regulariter 3juge pinnalisecta. Vaginae 4-6" Inngac, chartaceae, hansverse striatac, apice oblique aperlac aeque ac petioli sesquipedales, supra concavi subtus convexi, demum glaIrati, nitidi, initio tomento fusen detergibili tectac. Rachis 1'4" longa, supra acute bifacialis, subtus Ieviter conrexa tomentosa. Laciniac utrinsecus 3 subacquales, summis paulo brevioribus el latioribus, distantia 2--3" oppositac, elongato-oblongae, falcatac, longius acnminatae, chartaceac, rigidac, glanco-rirides $\mathbf{1}^{\prime}-\mathbf{1}^{\prime} \mathbf{2}^{\prime \prime}$ longae, hasi 3!" latae. Nervi primarii 7 -10, distantia trium linearum paralteli, imprimis supra prominentes, iuter quos alii, superne vix conspieui vel leviter impressi, tomeuto adspersi subtus decurrunt. Celera ignota. - A C. cleganti, Bronguiarlii, Desmarestii, quibus maxime affunis est, laciniarmm indole et imprimis petioli longitudlue facile distiuguitur.

Jeg hall fundet den pala samme Sted som den foregaacude.

\section{Tribus II. Coryphiuar.}

Af denne Afdeling har jegr luu iagttaget tre Arter i Centralamerikit, af lwilke deu cue syues at rere Copernicia tectormm Marl., den anden Thrinas argentea Lodd. og den tredir en 1 !

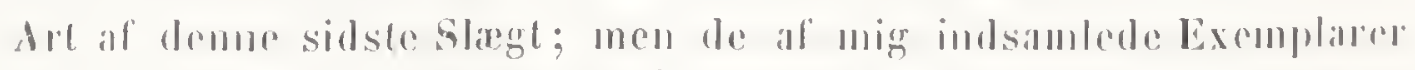

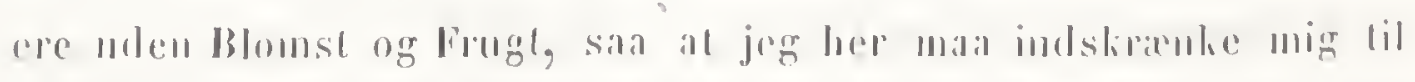

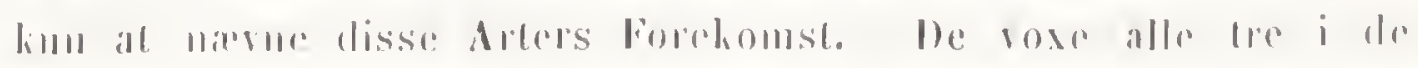

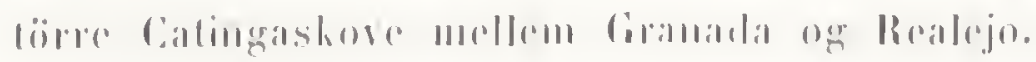




\section{Tribus III. Gocoinas.}

Augustimea Karsten, Plant. Columb. 51.

Char. emend. Flores monocei in codem spadice. Masc. Perigonium exterius parum tripartitum, laciniis membranaceis lanceolatis acuminalis; interius multo majus oblongum, trigonum, subobliquum, tripartitum, laciniis coriaceis nervosis inferne in stipite solido commatis. Stamina sex. Fem. Perigonium exterius el illlerius urceolata, coriacea; illud lroc superaus, basi intus mudum vel cum ammulo membranaceo lrifido comnatum. Urceolus stamineus minlitus, demum unacum perigonio excresecns el cum hoc collnalus, apice tantum liber. Orarium trigono-ovalum. Stigma truncatum. Drupa ovalis vel ovala cun brevi acumine, sacpius migro-violacea, basi perigonio aucto cupulari paene regulariter multilobo cincla, exocarpio coriaceo, mesocarpio pulposo-fibroso, cndocarpio ovali vel oblongo osseo vertice oblique tridentato, poris tribus lateralibus, uno pertuso superiore, duobus coecis inferioribus paulo supra medium positis. Semen ovale ad poros impressum, embryone laterali. - Palmae arundinaceac, caespilosac, aculeatac, 12-20pedales. Folia pinuata, rachi aculcis longis obsita, pinnis numerosis aequidistantibus rarius aggregatis margine aculeolatis. Spatha duplex; exterior minor lauceolata coriacea ventre concaviuscula ad margines carinato-dilatata, dorso convexa, landem irregulariler rumpendã; interior fusiformis, basi altenuali, sublignosa, aculeis dense obsila, tandem rentre Iongitudinaliler aperta. Spadix pedunculatus apice simpliciter ramosus, pedunculo compresso, ramis subumbclatis fastigialis crassiusculis rigilis.

Hoc gemus a Bactride distinguilur: perigonio flor, fem. exteriore interius superante, drupa majorc ovali, endocarpio orali vo oblongo tridentato, spadice subumbellato-ramoso.

Karsten har (l. c.) light Bactris major Jaer. til Grund for denuc Slagt, og som riesentligste Charalitece for samme narnlig udlarevet en hindeagtig Ring i IIunblomsten, som er sammenvoxen med det ydre Blomsterdickle. Det er mu vistnok meget rig- 
tigt at soudre denne Palıne fra Bactris som en egen Sliegt, men der bör neppe lægges megen Vægt paa den Charakteer, hvori Karsten söger den vesentligste Adskillelse fra Bactris; thi da vilde man faac en meget koustig Sondring mellem Arter, som ellers stemme fuldkomment overeens. Bactris infesta Mart., B. socialis Marl. og to nye eentralamerikanske Arter, som her skulle beskrives, slutte sig nemlig i alle Henseender meget nöie til B. major, men mangle denne hindeaglige Ring. Jeg foreslaaer derfor at forandre Charakteren for Augustinea, saaledes at disse Arler kunne optages deri, og narnlig lingge Vægl paa de Egenheder i Frugten, Blomsterdakkets Form og Blomsterstanden, hvorved disse Arter ere tydeligt og skarpt sondrede fra de typiske Former af Slægten Bactris.

Augustinea ovata sp. n.:

pinnis aequidistantibus linearibus strictis glabris margine setosoaculeolatis acumine inaequilateralibus, raclui supra bilaciali setulis fuscis interspersis puberula, subtus convexa tomento griseo vel fuscesecnte detergibili tecta aculeis $2-3$ pollicaribus compressis fuscis apice nigricantibus nitidis initio tomentosis sparsis vel geminalis obsita, spatha interiore inferme attenuata currata aeque ac pedunculo tomento fuseo adspersa aculeis nigricantibus dense obsita, spadicis ramis $11-12$, drupa ovata punctis elevalis seabriuscula, endocarpio ovali fusea punctis minutissimis elevatis scabriuseulo circa poros glabro albescente, dentibus obtusis, duobus majoribus.

Caudex 6-8' altus, rectus aut curvatus, cylindricus, gracilis, majore ex parte foliorum petiolis persistentibus vaginatus, aculeis armatus; plures in caespidem sat densum conferti. Folia 5 ' longa. Pimmac alternae, $1-14$ " Iongae, $\frac{1}{2}$ "latac, fuscescentivirides, nervo medio promimulo pallidiore, nervis secundariis el certiariis erebris valde approsimatis. Spatha pedalis. Pedunculus semipedalis; rami $11-12,3-4$ " longi, umbellatim congesti. Flores ignoti. Drupa 14-15" longal, pallide fuscia; en- 
docarpium $1 \mathbf{L}^{\prime \prime}$ longum - A. sociali valde alfinis, qualenus ex descriplione imperfecta hujus speciei concludere licel, esse videlur; certe vero distincta pinnis fere duplo breviorilus et imprimis drupa mullo minore fere ovata, endocarpii colore et forma et pororum silu facile distinguilur.

Jeg faude den ved Punto poderoso pa Nordsiden af Nicaragua Sï, med Frugt i Feloruar.

Augustinca balanoidea sp. n.:

spatha latius fusiformi fusco-lomentosa aculcis nigris subappressis obsila, pedunculo compresso curvalo lomentoso aculeis destilulo, ramis spadicis 8-12 umbellatim congestis, drupa ovali acuminc obluso lerminata fusco-violacea fere glabra, endocarpio elongato-ovali nigro glabro apice oblique tridentato, dente altero celeris longiore acuto.

Caudices 10-12' alti, graciles, cylindrici, aculeis armati, subcaespitosi. Folia desunt. Flores feminci medium ramum, lloribus masculis jam delapsis, dense oblegentes, Balanos minuIos, animalia illa crustacea forma tam insolita, referunt. Perigonium exterius a basi lata conico-urcelatum, tomento sublilissimo fusco conspersum, ferme integrum; interius urceolato-tubulosum, apice leviler trilobum, ovarium arcle amplectens, striatum, inferne fuscum, selulis minutissimis adspersum, basi annulo minulissimo carnoso demum unacum perigonio excrescente connatum. Ovarium glabrum, perigonium interius paubo superaus. Drupa cum perigonio basin stipante 11" longa, endocarpium 1" lougum. Species nostra, elsi folia desunl, ab A. majori, cui valde aftimis est, alssentia annuli membranacei in perigonio cxteriore facile dislinguitur; practerea flores feminei (secundum specimina milhi a cl. Karslenio benevole communicati) ommino diversi, imprimis perigonia in A. majori apice multo angustiora et urceolus stamiIutm multo majus.

Jeg har funclet demue Palme i den ypuige Skov öst for PunLarcuas paa Vestsiden af Costa Rica. 


\section{Bactris Jacq.}

Denne Slagt, den störste af alle amerikanske Palmesliegter, tranger mere end nogen anden til en omligggelig Revision; thi foruden de Arter, som cre lienförte til Augustinca, er der cudnu mange, som cre saa afvigende i Blomsteus og Fruglens Bygning og $\mathrm{i}$ deres hele Habitus, at det uden Tvivl vil vare rigligst at sondre dem som eguc Slagter, cller idetmindste som Underslagter. Sec vi hen til den Art, som ligger til Girund for Jacquins Bestivelsc af demne Slagt, nemlig B. minor, og de Arter, som slutle sig narmest lil denne (Maraja, inundala, pallidispina, Brongniartii, acanthocarpa, mexicana o. fl.), da viser det sig, at de vesentligste Charaliterer, hrorved disse Arter forenes, bestaac i en mangegrenct Kolbe, Iunblomstens ydre Blomsterdakke, som er mindre end det indre og nasten udeclt, en cylindrisk Frugtkmude ned siddende Ar og en kugleformet Frugt med et nedtrykt-kugleformet, nasten lindseformet Indrelag. Disse Forloold ville altsaa betegne Slagten Bactris i indslirenket Forstand (Eul)actris). En anden Rakke Arter, navnlig B. longipes, hirta, tomentosa, pectinata, aristata, cuspidata og fissifrons, slutte sig nöic sammen og udmarke sig ved en togrenct (sjelden udeelt cller faggrenct) Kolbe, ved IIunblomstens ydre Blomsterdakke, som nasten altid er meget lille og dybt tredecll, medens det indre er stort og oftest loddent, ved Frugtlinuden, som er axgformet og forlanget i cu kort Griffel, og firugten, sour er kugleformet med et topformet Indrelag. Jeg vil forestanc at henföre disse Arter til en egen Understegt (B a c tridiopsis). Fremdeles er der to Arter med udeelt Koble, som ere saa afrigende, at de maa sondes som egne Underslagter. Til den ene (Diplothemopsis) hörer B. concinna, som har en langstilket kollo med en meget tyk Axe og et langstilliet Iylster, lirorved den faner megen habiluel Lighed med Diplothemium, Humblomstens ydre ogr indre Blomsterdxkle rïrlanucde, niesten ligestore, lingten omvende irgformet og Indrelaget ovall; til den anden (Bactridelfa) hörer B. simplicifrous, con meget spinlict, fyndstammot Palme 
uden Torme, med et lille lancetdamet Hylster, luvis Humblomst er forsynet med rördannet, tretandet ydre og indre IBlomsterdiekke, og som har cu lille kugleformet Frugt med et kugleformet Indrelag. Hertil kommer endnu en femte Underslagt (Trichoba ctris), der navulig udmarker sig ved en eicudommelig Blomsterstand, og vil blive beskrevet i det fölgende.

Liarsteı lıar foreslaact (1. c. p. 49) at henföre de Arter, som have rudimentaere Stövdragere i Funblomsten, til cu cgen Slagt (Guilielma); men det vilde neppe vaere rigtigl, da de ellers i alle andre Henseender stemme overeens med Bactris. Tilstedevarelsen eller Mangelen af rudimentare Stijvdragerc, som her nasten altid lıve Form af en hindeagtig Ring, kan i mange Tilfalde vaere en Charakteer af förste Rang, naar den nemlig holder sig constant i Forbindelse med andre Egenheder i Blomsten og Frugten, men det finder ikke Sted hos disse Palmer, saa at man her ikle kan tillagge dette Forhold den Betydning, som Karsten har gjort, uden at gjöre et fuldstiendigt Brud paa den af Naturen anviste Begrandsning af Slagterne.

\section{Subgenus 1. Eubactris.}

Spatha interior fusiformis, aculcata. Spadix multiramosus, ramis strictis a basi ad apicem sensim attenuatis. Flores maseuli sessiles, raro brevissime pedicellati, per omnem spadicem sparsi. Flor. fem. perigonia cyliudraceo-urceolaria, fere truncata, exteriore minore sacpe anmuliformi. Ovariun prismatico-trigonum. Stigma sessile, trigonum. Drupa globosa vel sulgglobosa, endocarpio depresso sublenticulari. Palmac arundinaceac, caespitosac, aculcatac. Folia pimmata, aculcata.

\section{B. (Eubactris) horrida sp. n.:}

cacspitosa, caudice mediocri foliisque aculeatissimis, aculeis longissimis 3-4pollicaribus tetragonis albescentibus fusco-tomentosis demum glabris nitidis apice fusco-nigrescentibus aculissimis, rachi subtetragona supra tomento levi adspersa, subtus 
dense fusco-tomentosa, pimnis 5-7nis aggregatis lanceolatis rigidis strictis glaucis apice hidentatis aculeato-cilialis, aculeis in nervo medio paucis sparsis, spatha basi longissime attenuala fusco-tomentosa aculcis 2-3lincaribus fusco-apiculatis subappressis per omnem superficiem aequaliter adspersa, pedunculo compresso curvato fusco-tomeutoso, ramis strictis arreclis, drupa globosa nigro-violacea verlice acuta.

Caudex $6-S^{\prime}$ altus, cylindricus, gracilis, $S-9^{\prime \prime \prime}$ diamctro, foliorum petiolis persistentibus majore ex parte raginalus, fuscotomentosus, ligno exteriore nigro duro. Folia $2 \frac{1}{2}-3^{\prime}$ longa. Vagina S" longa, cylindrica, fusco-tomentosa, apice oblique

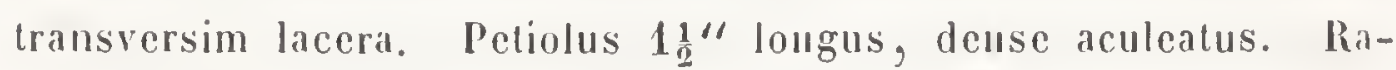
chis 2-2 $\frac{1}{2}$ longa. Pinnac $7 "$ longae, 6"latae, solo nervo medio supra prominulo. Spatha exterior semiteres, lanceolata, acumiuata, fusca, 10" longa, veutre concaviuscula glabra ad margincs carinato-dilatata, dorso convexo tomentoso. Spathae interioris pars inferior tenuis cylindrica spatha exteriore vaginata, $10^{\prime \prime}$ longa, inferuc clausa, pars superior fusiformis 5" longa, acumillata, aperta cymbiformis, intus fusca, glabra. Pedunculus 10"

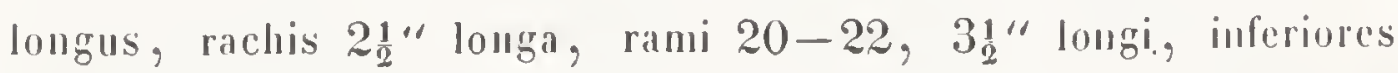
bracteis lauceolatis 8“" longis stipati. Flores ignoli. - Haece species B. Maraja, Brongniartii, tenerae (Guiliclmac tenerae Karst.) et imprimis B. pallidispino affinis petiolo brevissimo, pinnis parvis apice bidentatis, aculcorum colore, spadice longissime altenuato et multis aliis notis facile distinguitur.

Den roxer paa Vestsiden al Nicaragua og Costa Rica i de töre Calingaskove pa saadanne Steder, som oversiommes i Regntides, men livor Jorden (Leer) i deu törre Till dammer cu steenhaard Masse. Jeg fandt den ved Bolson i Provindsen Guanacaste og $\mathrm{i}$ Narheden af Granada med modne Frugter i Februar. "Uviscoyol" el det Nivil, lwormed Landels Bebocre betegue denue Palme, ligesom de lleste Arter af Slagten Bactris. De saftige, syrlige fruzter spises og benyttes isier, efterat vare kuuste i Vand, til en laelskende Drik. 
B. (Euloactris) fusca sp. n.:

fusca, aculeato-setosa, foliis parvis longepotiolatis, rachi supra tomento setis brevibus intermixtis sultus setis longioribus fusconigrescentibus densis tecta, pinnis 2-4nis aggregatis lincaribus acuminatis setoso-cilialis supra levius subtus dense pubescentibus pallidioribus, in nervo medio setis sparsis, nervis secundariis utrinsecus 4 prominüis, spatha fusiformi acuminata basi attenuata curvata dense aculeato-setosa, setis aculeisque apicem versus multo longioribus nigrescentibus, pedunculo compresso curvato tomentoso apicem versus setis appressis tecto, ramis 2 -5 adrectis strictis tomentosis, floribus masculis brevipedicellatis; ovario perigonio interiore fere duplo longiore, drupa fusca subglobosa, mesocarpio tenuissimo, endocarpio tenui depresso fere semiglobosa basi applanato, poris tribus maximis lateralibasilaribus.

Folia 3-4' longa; vagina $7-8^{\prime \prime}$ longa, fuseo tomentosa, setosa, dorso aculeis semipollicaribus obsita; petiolus 7-S" longus, rachis lipedalis; pinnac $8-9^{\prime \prime}$ longae, 5" latac. Spadices rami tripollicares, bractca triangulari $1-2^{\prime \prime \prime}$ longa suffulti. Flores feminei glabri; perigonia levissime tridentala; cxteriore annuliformi, interiore brevi-tubuloso margine inter dentes glanduloso-ciliato, ciliis aggregatis. Drupa Pisi majoris magnitudine.

Denne Palme, som ikke er nöie beslagtet med nogen anden Art, har jeg fundet paa Östsiden af Costa Rica i de yppige Urskove ved Turrialva $\mathrm{i}$ en Höide af c. 3000' med Blomst og Frugt i April.

\section{Subgenus 2. Tricholactris.}

Spatha interior lusiformis, villoso-setosa. Spadix ramosissımus; rami filiformes flexuosi, pars inferior incrassala rachi appressa, floribus femineis sceundis, interspersis masculis, instrueta, pars superior tenuissima floribus femincis destituta, masculos solos gerens. Flores masculi pedicellati, trigono-oblongi, peri- 
gonio interiore trifido, Iaciniis basi in stipite solido commatis:) Fem. perigonia cylindraceo-urceolaria ferc truncata, cxteriore breviore. Ovarium prismatico-trigonum. Stigma sessile, Irigonum. Drupa? - Palma mediocris, aculeolata. Folia aggregato-pinnata, pinnis arrectis apice bifidis.

\section{B. (Trichobactis) sp. II.}

foliis aggregato-pinnatis, rachi robusta supra bifaciali levius pubescenti-tomentosa, subtus convexa tomento denso fuscescente tecta, demum glabrata, aculeis nigris quadrilinearibus inferme sparsis apicem versus deusioribus obsita, pinnis Iongissimis tenuibus quinis confertis linearibus arrectis glaucis setoso-ciliatis apice bifidis, supra glabris subtus pubescentibus, mervo medio lato applanato superne aculeolis bilinearibus nigris densioribus obsito inferne nudo, nervis secundariis utrinsecus 3 prominulis, spatha interiore fusiformi liguosa inferme attenuata curvata selis flavescentibus nitidis densissimis per totam superficien xqualiter tecta, pedunculo compresso curvato dense setoso, ractri ramisque fusco-tomentosis.

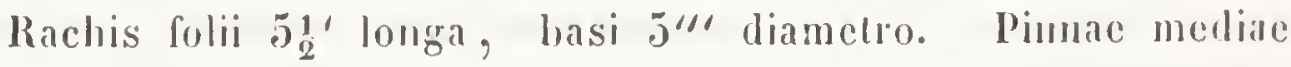
L" longae, go"latac, superiores sensim decrescentes, summis conflucntilus. Distantia inter greges 12". Rachis spadicis $3 \underset{2}{1}$ " longa. Ramormm pars inferior incrassatid $1^{\prime \prime}$ supcrior filiformis 2-2! "longi. Fores masculi glabri pedicellati, pedicellis basi glanduloso-pitosis; perigoniun caterius minutum, triangubre, uncmbrauaceun, trifidun, laciuiis acutis, interius coriaccum, trigono-oblongum, trifidum, laciniis triangularibus acutis. Flores feminei bilincares, secundi, arrecti. Perigonia allicantia, longitudinaliter striata, pilis fuscis couspersil, truncata, leviter trideutata; exterins fere cupulare, interius tubulosum orarium acquans.

*) Hanblousterne ere ikke endun tilstrakkelig undersögte hos alle Arter at kunne afgujore, lwor megen Veget der kan leggges paa deme Charalileer. Ilos nogle Arter synes filigrne at vare frie narsten lil Girunden (t. Ex. hos B.tomentosa). 
Ovarium trigonum, glalsum, lucriter slipilitum, infra stigma parum coustrictum. Stigma trigoum subtrilobmm.

Voxer paa samme Sted som den foregaacnde.

\section{Ginilielma Mart.}

Karsten mener, at denne Slagt ilike er vel hegrundet af Martius, og at de af dennc Forfatter licrunder opförte Arter bül forenes med Bactris (I. c. p. 49). Derimod foresliacr laan al sondre de Arter af Bactris, som lave rudimentare Stördragere i IIunblomsten under Form af en lindeagtig Ring, som en egen Sloggt, paa disse at overfürc Navnet Guilicha og under Bactris kun belıolde de Arter, som mangle denne Ring. Jeg lıar allerede ovenfor gjort opmarksom paa, at man lice iklic kan benylte Mangelen eller Tilstederarelsen af denne Ring som eneste og viesentligste Slægtscharakteer uden at gjöre et fuldstaudigt Brud paa den af Naturen anviste Begrandsning af disse Slagler, da den staace uden Forbindelse med andre viglige Forskjelliglieder i Blomst og frugt; men liertil komner endnu, al Ciniliclma i den Forstand, hrori den er opfatlet af Marlius, uden al Trivl maa ansces for en megel gorl og vellucgrmndel Slagt. Sec vi nemlig hen til den Art, hrorpa den er byggel (G. speciosa, Bactris Gasipaes 1Iumb). el Kunth) - de to Arter (G. insignis og G. Macana), som sencre cre tilföiede, cre kun saa ufuldstandig lijendte, at det endon er tvivlsomt, luvorvidt de höre herlen la finde vi, at den navnlig i Frugten, der luer som hos de fleste Palmer afgiver de bedste Slongtscharahterer, er saa forskjellig fra Bactris, at det vilde stane $\mathrm{i}$ Strid med de mu grjeldende systematiske Regler at bringe dem sammen i cen Slingt. Guiliclma adskiller sig nemlig fra Bactris ved en keglefermet Frugl med et kjödet, mecllıbligt Mellemlag og el omveudt kegleformel Indrelag, bekladt med et natformigt Prevlelag, foroven afstumpet med eu lille Spids pa Millen ogg tre Porer i Omkerasen. Hertil liommer combur et mesten lingloformet indro Blamstordalie hos Han- 
blomsten, et meget lille næsten forsvindende Ar og en fra Bactris afvigende Habitus, da de herhen hörende Arter ere anseclige Træer med en stor oprel Blomsterstand, et cylindrisk Ydreliylster og et kölledannet Indrehylster.

\section{Guilielma utilis sp. n.:}

caudice erecto elato tereti distinctissime annulato; spatha interiore lignosa subclavata acuta extus tomento denso fuscescente tecta aculeis semipollicaribus nigris reflexo-appressis flavescentibus tenuioribus intermixtis dense obsita, pedunculo compressotereti tomento brevi fusco consperso bracteis bipollicaribus lanceolatis crassis coriaceis instructo, ramis spadicis flexuosis basi bractea lanceolata acuminata suffultis, floribus masculis pedicellatis, pedicellis rigidis persistentilus, perigoniis floris feminei margine levissime trilobis, drupa globoso-conica olstusa glabra striis longitudinalibus latis fuscis notata, endocarpio obconico basi obtuso verlice applanato apiculato, semine ovali.

Affinis G. speciosae, a qua tamen facile distinguitur caudice, cujus internodia brevissima zonis triangularibus nigris aculeatis et albicantibus nudis alternantibus peculiarem pracbent habitum, spathae interioris vestimento, bractearum forma, ramis flexuosis, floribus masculis pedicellis instruclis, drupa striata, endocarpio basi obtuso et semine ovali.

Denne udmarkede Art voxer i Costa Rica paa den ösllige Skraning i de yppige Urskove i en IIöide af 2500-4000 Fod. De melede Frugter (omtrent af Form og Störrelse som et stort pigconeble) have, naar de ere kogte, temmelig megen Lighed i Smag med Kartofler, og udgjöre paa flere Steder et af de vigligste Nieringsmidler blandt Jndianerne. I San José og Carlago sane jeg ofte disse Frugter udbredte pa Torvet i store Bunker, naar de bragles tilsalgs af Indianerne fra Orosi. Ved Hacienda de Ujaras lar jeg seet dyrkede Exemplater. Den kialdes al Landets Behocre "Pechevaye”, men jeg tiir ihler afgjöre, om delle Navu er af indiansk eller spansk Oprindelse. -- Jeg har oventior 
ikke meddeelt nogen Beskrivelse af Bladene, som vel ikke mangle i mit Herluarium; men da jeg ikle selv har havt Leilighed til at samle dem - de ere efter Anmodning bragte mig af Indianere og da de i det Ifele ere meget afrigende fra dem lios G. speciosa, saa har jeg nogen Formodning om, at der maaskee er skeet en Forvexling, og at disse Blade muligen tillı̈̈re en anden Palmeart.

\section{Acrocomia Mart.}

Til de af Marlius angivne Charakterer for demne Slagt maa föies, at hver Hanblomst er forsynet med et lille Dxkblad, der ligesom ved Hunblomsten er skjult i den lille Grube, hvori Blomsten er nedsænket. Stövtraadene ere iklie rigtig beskrevne eller afbildede. Martius har nemlig overseet den överste Deel af Störtraaden, som er meget tynd og slaact tillbage, livorfor ogsaa Stövknappens Tilhæftning er urigtig fremstillet; denne er nemlig list over Midten og ikke i Nærheden af Spidsen.

\section{Acrocomia vinifera sp. 11.:}

caudice 40 pedali erecto cylindrico brevissime annulato vaginarum basibns persistentibus tecto aculeis armato, nunquam medio tumido, foliis arcuato-reflexis, pinnis linearibus numerosis, basi petioli et rachi aculcatis, aculeis tripollicaribus compresso-planis nigro-fuscis glabris nitidis margine tomentosis, spatha fusiformicylindrica longissime acuminata tomento densissimo fusco setis rigidis nitidis arrectis immixlis tecta, acumine 7-spollicari compresso in latere ventrali medio aculeis arrectis obsita, pedunculo aculeis paucis adsperso, floribus femineis bracteolis duabus minutissimis triangularibus lateralibus oppositis et appendiculis duabus filiformilus rachi appressis stipatis, drupa globosa fuscoflavescente basi ferc conica vertice stigmatis basi persistente mucronata.

Caudex triginta ad quadraginta pedes altus, reclus, aequaliter cylindricus nec unquam medio tumidus, diametro ad basin 
pedali, vaginarum hasibus persistentibus teetus, aeuleis horridus, dum junior adhue vaginis superstitilus quasi cataphractus. Spatha tripedalis vel paulo longior, elausa tres polliees diametro; spadix 8-9 poll. brevior. Flores masculi in alveolis glabris densissime imbricati, obovato-oblongi, mutua pressione angulati, parum ohliqui, bracteola minutissima triangulari stipati. Perigonii exterioris foliola minutissima, oblonga, obtusa, margine albicantia, interioris olılique oblonga, obtusa, coneaviusculal, subinaequalia, crassa, striata, basi comnata. Stamina basi perigonii inserta, filamentis apice tenuissimis replicatis, antheris linearihus paulo supra medium affixis. Pistillnm abortivum minutum, trigounm, stigmatibus tribus brevilus erectis terminatum. Flor. fem. perigonii exterioris foliola parva, triangularia, obtusa, striata, margine membranaeea albicantia, interioris foliola suborbieularia, coneara, crassiuscula, striala, imbricata, margine tenuiore allsila. Urecolus stamineus eum perigonio comnalus, apice tantum liber, sexdentatus, dentium loco interdum staminilus rudimentariis instruetus. Ovarium Irigono-obovatum tomentosum, inferne glabrum. Stigmata tria subulata, supra canaliculata, revoluta. Aflinis $\Lambda$. lasiospathac, a qua tamen, quantum ex imperfecta luujus speeiei descriptione coneludere licet, satis diferre videtur et eaudice nunguam tumido et spathac forma et restimento.

Denue Palme har en temmelig stor Udloredung paa Vestsiden af Nicaragua og Costa Riea og forekommer isar i Mrengde i de lave vulkanslie Dale, i en Itoide af omtrent 500-1000 Fod over Havet. Paa saadanne Steder danner den smaa Skove uden Indhlanding af andre Trxer (saaledes paa Sydsiden af Vullianen El Vicjo, i Proviudsen Guanaeaste i Nierheden af Ilacienda Santil Rosa ved Tierra blancal), et Fordold som handt alle de Palmer, jeg har truffet i Centralamerikia, kun er ciendommeligt for demme og for Raphis taedigera, medens alle de andre forekomme spredte, men aldrig danne sammenhengende Skovparticr. Satadanne Slione

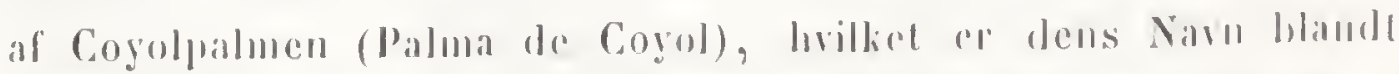
Landels Behoere, have et ganslie eiemdommoligh l'rieg. De unge 
Stammer ere ligesom bepandsrede med Bladskederne, som blive sildende i flere Aar; de gamle derimod stritte af lange sorte Torne og rage stivt iveiret til en Ilöide af 30-40 Fod. IIer findes i Reglen ingen Underskov, som udfylder de temmelig store Mellemrum mellem Stammerne; men Jorden er kun bedækket med stivt Gras, der afbrændes i den törre Aarstid, hrorfor Palmestammerne gjerne ere sorte og forkullede forneden. Coyolpalmen voxer meget langsomt, og antages först $i$ en Alder af 100 Aar at opmaac en Höide af 40 Fod. Den er en af de nytligste Palmer i Centralamerika, da Frugterne i den törre Aarstid, naar Savannerne afbræudes, tilligemed Bladene af Acaeierne paa mange Steder afgive det eneste Nieringsmiddel for de store Flokke af Hornqvag, som her udgjöre Beboernes vigtigste Rigdomskilde. Af Frugterne presses desuden en fortrinlig Olie, som baade benyttes til Madlavning og til at briende. Stammen indeholder, naar Blomsterstanden er i Begreb med at skyde frem, en sukkerholdig Væalske i rigelig Mængde, Lvoraf man tilbereder et Slags Cider, den saakaldte Coyolviin, som er ret velsmagende og ansees for meget sund. For at erholde denne Vadske, bliver Palmen fixldet og Kronen aflugget; derpaa gjöres en stor firkantet Fordybuing i Stammen lige ved Toppen; heri vedbliver nu i Libut af 20 Dage at samle sig saa megen Vadske, at man kin regne 2--3 Flasker i Gjennemsnit om Dagen. Ved demne ödelieggende Fremgangsmaade ere Coyolpalmerne allerede paa mange Steder nasten udryddede, hrorfor man ogsaa $i$ den senere Tid har forbudt at fielde dem i Nærheden af Qvaghaciendaerue.

\section{Ittalea II. B. K.}

Attalea (?) go mplioeocea Mart. Ilist. Palm, 3.301 t. 167 f. VI: carudice elato, 30-40' alto, juniore vaginis foliorum persistentibus quasi eataplıracto, foliis longissimis pinnatis, vaginis latissimis margine in fibras solutis, petiolis brevissimis, pinnis numerosis lineari-lanceolatis faleatis coriaceis reduplicatis margine 
incrassatis apice tandem bifidis flavescenti-viridibus, supra nilidulis irideis, subtus opacis, 2 ' 3 "longis, $2^{\prime \prime}$ latis, nervo medio robusto tetragono, nervis secundariis vix conspicuis, nervulis transversis flexuosis densissimis, spatha fusiformi lignosa, spadice ovali demum reflexo, putamine oblongo vertice tridentato basi rotundato fibris rigidis poros obtegentibus stipalo, sub fibros pyramidato-attenuata, semine clongato-ovali.

Jeg maa beklage, at jeg ikke kan give nogen Beskrivelse af Blomsterne*) af denne hidtil kun meget ufuldstændig kjendte Palme, da jeg foruden en Tegning af et ungt og et udvoxet Exemplar, som fandtes i Nærheden af en IIacienda (hvor de formodentlig vare plantede) i Provindsen Guanacaste, kun har hjembragt en Deel af et Blad og Frugter. Disse stemme nöie overeens med den af Martius meddeclte Beskrivelse og Afbildning, naar man undtager, at han ikke omtaler de Fibre, som bedxkke Porerne; men de have rimeligviis været afrevne paa de af ham undersögte Frugter. Den bærer Navn af Palma real.

A ttale a Colu une Mart. Hist. Palm. 3. 101 t. 167 f. IV

skal ifölge Loddiges lıave lijemme i Honduras, livor den af Landets Beboere benævines Colıune.

\section{Attalea (?) rostrata sp. H1.:}

caudice stricto cylindrico laevi crasso arcte annulato, foliis longissimis erecto-patentibus, rachi triquetra lignosa, supra aculangula glabra flavescente, subtus plana tomento densissimo furfuraceo fusco tecla, pinnis numerosis densis suboppositis lincaribus falcatis reduplicatis marginatis apice demum bifidis, spathis fusiformibus longissimis longiludinaliter sulcatis tomento fusco furfuraceo detergibili tectis apice in rostrum longissimum solidum compressum acutum productis.

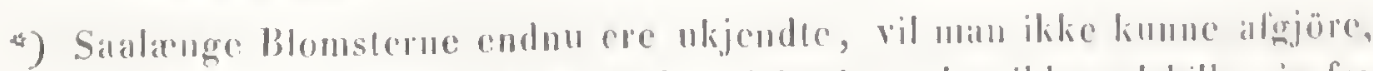
our denne Art liörer til Atualea eller Scheclea, der ilse adsille sigr fra fiuanden uden ved formen al det inde Blomsterdalkes Blade i llanblomsten, som hos sidsturevite ere trinde. 
Caudex 15-20' altus. Folia 12-15' longa. Pinnae ferme tripedales, 2 "latac, coriaceac, glaucescentes, nervo medio valido triquetro supra prominente, lateralibus utrinsecus $6-7$ subtilissimis, nervulis transversis densis flexuosis. Spathae 5-6' longae. Cetera ignota.

Da jeg ikke kjender Blomsterne, kan jeg ikke med fuldkommen Sikkerhed afgjöre, om dennc Art hörer til Slægten Scheelea eller Attalea, hvilken sidste den ifölge sin Habitus kommer nærmest. I Hylsterets Form og Störrelse har den mest Lighed med Attalea b!epharopus Mart. - Jeg lıar ikke truflet den uden paa Vestkysten af Costa Rica ikke langt fra Puntarenas, hvor den voxer sammen med Elacis melanococca i den store Skov, som strakker sig mellem Palmar og Esparsa.

\section{Elaeis Jacq.}

Elacis melanococca Mart. var. semicircularis:

candice semicirculari decumbente radicante, petiolis spinis aduncis apice indivisis mmitis, pinnarum nervis secundariis duobus subtus prominulis, tertiariis sex, pedunculo spadicis feminei compresso, bracteis ad basin ramorum lato-triangularibus acumine longissimo subulato terminatis, bracteolis tribus flores femineos cingentibus triangularibus inaequalibus acstivatione imbricatis.

Denue Palme er i saa mange Punkter forslijellig fra Elacis melanococca Mart. - idetmindste efter Beskrivelsen at slutte at den maslice ma danne en egen Art; men da jeg ikke har havt tilstrækkeligt Materiale til Sammenligning, har jeg dog anseet det for rigligst indtil videre kun at opföre den som en Varietet. Ifölge den Beskrivelse, som Karsten nylig har med. declt af Elacis melanococea ${ }^{*}$ ), er den centralamerikanske Palme isier afvigende i Formen af de tre Dikkblade, der omgive Hnnblomsten ligesom et ydre Blomsterdickic. - Den roxer paa

s) Plantac columbiaceac i Linnaca for 1857. 
Vestsiden af Costa-Rica ved Palmar, hvor den dammer en Underslior af et hioist cicnlonmeligt Udsecnde. Den korte, lykke Stamme er ncmlig nedliggende, halveirkelformig krummet og udsender lalrige Rödder, hvorved den er haftet til Jorden, sa at den har Incgen Lighed med en stor overjordisk liodstok; kun Toppen laxer sig iveiret, og den store Krone af finncde Blade, der sprede sig regelmiessig til alle Sider, hviler paa Jorden; imellem de tornede Bladstilke skinne de mönnieröde Frugler frem, samlede i store Hoveder. Den berer blandt Landels Jndrancre Navn af Palmiche. Frugternc anvendes isæer som Föde for Fjerkreaturer.

\section{Tribus IV. Iepilocaryinae.}

Af denne Tribus har jeg kun truffet en Art af Slaglen Raphia, som kun er liclet forskjellig fra R. taedigera Marl., men dog synes at vere en egen Art og passende vil kumne kaldes R. nicaraguensis, da den neppe forekommer udenfor Nicaragna. Den arlskiller sig fra R. Aachigera red Bladene, hris Finner stane namere himanden, alle lave samme Retning og mangle Torne i Randenc. Desuden er det inderste Dakblad (spathellula) ilike Indskaret i Spidsen, og det ydre Blomsterdaklie er störe i Forhold til det indre; men da Blomsterme par de af mig indsamlede Exemplarer ikke ere heelt udviklede, skal jeg her imlslirenke migr til at antyde disse Forskjelligheder og overlate til fremtidige Undersïgelser at afgjöre, hrorvilt de kunne tillagges Betyduing som Artsmarker.

Denue Palme kaldes i Nicaragua "Holillo" og er indskramhet (i) Floden San Juan's örre og nedre Delladannclse, hror den uden Indblanding af andre Treer damer store sammenlaxugende Skove. I Regntiden orersvïmmes de flade, smmpige Egne, hor

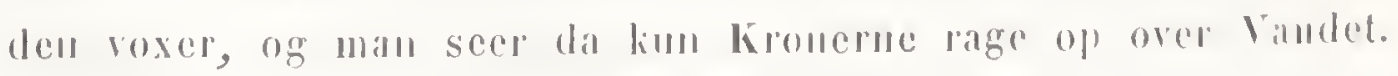
Jegr fande den med Blomst i Begrydelsen af Marts. 
Medens, denne Afhandling har varet under Trykken, har 11. Wendland, af hrem vi tör vente mange vigtige Oplysninger om Centralamerikas enduu kun lidet kjendte Palmer, viist, at den Palme, som ovenfor (l'ag. 5) er opfört under Narn af Collinia(?) fibrosa Wendl, danner Typus for en egen Slagt (Synechanthus Wendl.), hroraf der desuden forckommer en anden Art (S. Warscewiczianus Wendl.) i Costa Rica* ${ }^{*}$.

Alle vore Kundskaber om Centralamerikas Palmer skyldes det sidste Decennimm, da der i Martius's store Værk neppe omtales mere end cen Art (Attalea Cohume) herfra. Foruden de, som ere beskrevne ovenfor, naever Warscewicz 27 Arter fra $0 \mathrm{~m}$ egnen af St. Thomas paa Östsiden af Guatemala ${ }^{{ }^{*} z^{2}}$ ); tages disse med i Betragtning, vil den centralamerikanske Flora talle 60-65 Arter af denne Familie, nemlig 32-35 Arecinae, 2‡-24 Cocoinae, 5 Coryphinae og 1 Lepidocaryinae. Et meget overveiende Antal Arter (c. 50) tilhöre den östlige Ileldning af Cordilleren eller Urskovbltet fra Havets Niveau til $4-5000^{\prime}$. I den lavere Deel af dette Balte, som man paa Reisen gjennem Floden san Juan til Nicaragua Sö larer at kjende nasten i hele dets Brede, spille palmerne ganske samme Rolle som i Sydamerilias Urshove, sabledes som det slildres af Humboldt, Martius og Brödrene

*) Botanische Zeilung I858 Pag. 145.

**) Disse ere: Geonoma acaulis, multiflora, elegans, simplicifrons, armndinacea, pendula, Enterpe oleraeca, Chamaedorea 3 sp. nov., Hyospallac elegans, kunllia montana, K. caryotoides sp. n., Manicaria saceifera, Trinax argentea, Corjpha sp.n., Astrocaryum Mnrumuru, vulgaris, mitis, Bactris Waraja, acanthocapil, mitis, Jesmoncus ortharamelus, polyacanllus, polyjlyllus, Allalca compla, Coeos botryophora, capitata. Demo Forerguedse er meddech af Warscewicz under hans Ophold i St. Thomas og kan derfor dike lillagges stort Vard med Ilensyn lil Arternes liestemmelse; men secr man hen lil Palmemes meget sma Udluredningspharer, (ör Inan vistnok antage, at de saa godt som alle ere andre Arter end dre, som forekomme i Nicaragua og Costa Rica (Ono u. J)ietrich, Allg. (Barเen\%. 1. 253). 
Schomburgk. Det er her foruden Raphia især Geonomer, Euterper og Iriartecr, som ere fremherskende. I en Hijide af 2-4000' forekomme tildecls andre Arter af samme Slægter (Geonomer, Euterper), men det er dog isar Chamaedoreerne, som her have deres Hjem. Pail de Bjerge, som i Costa Rica hære sig over Cartagos Höislette (fra 5000 til $11000^{\prime}$ ), har jeg ikke truffet en eneste Palmc. - Paa de lavcre IIöisletter, som vende imod Vest, og paa hele den vestlige Skraaning af Landet kunne Palmerne i det Hele neppe siges at udgjöre nogen charakteristisk Bestanddeel af Skovene - de saakaldte Catingaskove - og det ringe Antal Arter, som findes her, henhöre til Cocoineernes og Coryphincermes Tribus, medens Arecineerne og narnlig Chamacdoreerne og Geonomerne ganske synes at mangle. Palnicrne have i denne Deel af Landet overhovedet et ganske andet Præg end paa Östsiden, de stemme nemlig overeens ined de her mest fremberskende Træer i en overordentlig stor Rigdom paa Torne, som ofte ere meget lange og spidse og beklicde nasten alle Plantens Dele, og ligeledes i en mere graalig Farve af Bladene. Acrocomia vinifera, Bactris horrida, Augustinca ovata, Copernicia tectorum(?) og Trinax argentea(?) ere de Palmer, som have den stiirste Udbredning i denne Deel af Centralmerica. 




New York Botanical Garden Library
QL 36 . A 1 O 751858 gen
rsted, A. S./Palmae Centroamericanae

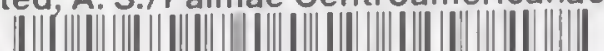

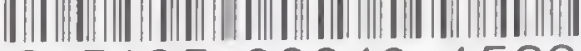

35185000401529 
